Article

\title{
Energy Performance of 3D-Printed Concrete Walls: A Numerical Study
}

\author{
Thadshajini Suntharalingam ${ }^{1}$, Irindu Upasiri ${ }^{2}$, Perampalam Gatheeshgar ${ }^{1}$, Keerthan Poologanathan ${ }^{1, *(D),}$ \\ Brabha Nagaratnam ${ }^{1}$, Paulo Santos ${ }^{3}$ D and Heshachanaa Rajanayagam ${ }^{1}$ \\ 1 Department of Mechanical and Construction Engineering, Faculty of Engineering and Environment, \\ Northumbria University, Newcastle upon Tyne NE1 8ST, UK; \\ thadshajini.suntharalingam@northumbria.ac.uk (T.S.); g.perampalam@northumbria.ac.uk (P.G.); \\ brabha.nagaratnam@northumbria.ac.uk (B.N.); heshachanaa2.rajanayagam@northumbria.ac.uk (H.R.) \\ 2 Department of Civil Engineering, Faculty of Engineering, University of Sri Jayewardenepura, \\ Ratmalana 10390, Sri Lanka; irinduupasiri@gmail.com \\ 3 ISISE, Department of Civil Engineering, University of Coimbra, 3030-788 Coimbra, Portugal; \\ pfsantos@dec.uc.pt \\ * Correspondence: keerthan.poologanathan@northumbria.ac.uk
}

check for updates

Citation: Suntharalingam, T.; Upasiri, I.; Gatheeshgar, P.; Poologanathan, K.; Nagaratnam, B.; Santos, P.; Rajanayagam, H. Energy Performance of 3D-Printed Concrete Walls: A Numerical Study. Buildings 2021, 11, 432. https://doi.org/ 10.3390/buildings11100432

Academic Editors: Francisco López Almansa and Jorge de Brito

Received: 16 August 2021

Accepted: 21 September 2021

Published: 25 September 2021

Publisher's Note: MDPI stays neutra with regard to jurisdictional claims in published maps and institutional affiliations.

Copyright: (C) 2021 by the authors Licensee MDPI, Basel, Switzerland. This article is an open access article distributed under the terms and conditions of the Creative Commons Attribution (CC BY) license (https:// creativecommons.org/licenses/by/ $4.0 /)$.

\begin{abstract}
Three-dimensional-printed concrete (3DPC), which is also termed as digital fabrication of concrete, offers potential development towards a sustainable built environment. This novel technique clearly reveals its development towards construction application with various global achievements, including structures such as bridges, houses, office buildings, and emergency shelters. However, despite the enormous efforts of academia and industry in the recent past, the application of the 3DPC method is still challenging, as existing knowledge about its performance is limited. The construction industry and building sectors have a significant share of the total energy consumed globally, and building thermal efficiency has become one of the main driving forces within the industry. Hence, it is important to study the thermal energy performance of the structures developed using the innovative 3DPC technique. Thermal characterization of walls is fundamental for the assessment of the energy performance, and thermal insulation plays an important role in performance enhancements. Therefore, in this study, different wall configurations were examined, and the conclusions were drawn based on their relative energy performance. The thermal performance of 32 different 3DPC wall configurations with and without cavity insulation were traced using validated finite element models by measuring the thermal transmittance value (U-value). Our study found that the considered 3DPC cavity walls had a low energy performance, as the U-values did not satisfy the standard regulations. Thus, their performance was improved with cavity insulation. The simulation resulted in a minimum thermal transmittance value of $0.34 \mathrm{~W} / \mathrm{m}^{2} \cdot \mathrm{K}$. Additionally, a suitable equation was proposed to find the U-values of $100 \mathrm{~mm}$-thick cavity wall panels with different configurations. Furthermore, this study highlights the importance of analytical and experimental solutions as an outline for further research
\end{abstract}

Keywords: 3D-printed concrete; sustainability; energy performance; U-value; finite element modelling

\section{Introduction}

The future sustainability of the built environment and the significant potential contribution of energy-efficient buildings have become crucial concerns nowadays. The construction industry is one of the sectors that requires substantial improvements to reduce its adverse effects on the environment and climate change [1,2]. This industry has a great influence on the environment in its energy utilization, as it uses more than $50 \%$ of all raw material globally, releases the largest amount of carbon, and is accountable for $40 \%$ of total energy consumed globally [1,3-6]. Hence, the perception of sustainable development in the construction industry is gaining attention, with increasing awareness of environmental 
protection laws. A built environment with minimized energy consumption has become the prime objective these days. In order to achieve this, new development practices, resources, and approaches are being pursued by current industries and researchers [7]. In addition to energy efficiency, lightweight material also provides sustainability by means of reducing material costs and related emissions incurred throughout the production. Hence, there is a necessity to use some regulations and initiatives to achieve these interests to enhance the energy efficiency in buildings [8].

\subsection{Three-Dimensional-Printed Concrete (3DPC) and Sustainability}

Over the past decade, the interest in the pursuit on extrusion-based 3D-printed concrete (3DPC) has been increasing exponentially. This innovative technology has been recognized as a sustainable green construction and environmentally friendly solution, as it reduces the overall construction waste and costs [9-12]. The integration of 3DPC in the design and construction of built environments brings many promising advantages, such as minimal manpower and labor costs, rapid fabrication, reduction of construction wastes, cost-effectiveness, formwork-free construction, and increased flexibility with precise architectural design. In addition to conventional building components, entirely unique and complex configurations, which are not viable with conventional formwork, can be constructed using 3DPC [10,12-15]. In addition, 3DPC provides lesser self-weight structures with topology optimization, and further reduction of weight and enhanced thermal insulation properties could be achieved by developing mix designs using materials with low thermal conductivity $[16,17]$. While 3DPC is regarded as a revolutionizing and innovative manufacturing technology, the creative conception and application of such a technology is still underexplored. Moreover, to fully utilize such a new technique, a deeper understanding of the process, from the design phase to the postprocessing phase, is required. However, researchers are focusing more on the structural performance of 3DPC structures, and numerous research studies are ongoing worldwide [18-22].

\subsection{Types of 3DPC Cavity Structures}

The 3DPC technique offers design flexibility with the inclusion of air cavities in the wall panels while satisfying both structural and thermal performance criteria. Different cavity provisions will also influence the thermal behaviour of the overall structure due to the concurrent occurrence of conduction, convection, and radiation heat-transfer processes [23]. Therefore, the printing parameters should be chosen wisely in order to achieve sustainable and energy-efficient 3DPC structures. Currently, 3DPC wall panels with different thicknesses and cross-sectional arrangements are used in the industry for better thermal and acoustic characteristics. Figure 1 shows some of the actual 3DPC wall panels with different cross-sectional geometries that have been developed to be structurally stable. Wang et al. [24] developed a systematic approach to explore optimization of the mechanical capacity of 3DPC cavity structural elements with different internal cross sections. Beam elements have four different types of interior cavity structures: cellular-shaped, truss structure, lattice-shaped structure with a square topology, and grid-shaped structure with triangular topology. Figure 2 shows the wall configurations studied structurally by Wang et al. [24].

\subsection{Energy Efficiency of 3D-Printed Concrete Structures}

Many design guidelines and performance criteria are available for the thermal performance of normal concrete, whereas very few studies have evaluated the thermal energy behaviour of 3DPC structures to date. The standard approach to determine the energy performance is the quantification of the thermal transmittance value (U-value), which is extensively used in Europe [2,23]. The thermal transmittance is a measure of how much heat will pass through one square metre of a structure when the air temperatures on either side differ by one degree $\left(\mathrm{W} / \mathrm{m}^{2} \cdot \mathrm{K}\right)$. The $\mathrm{U}$-value depends on the thermal conductivity $(\lambda)$ of the material and its thickness $(d): U=\lambda / d$. Therefore, lower U-values or higher energy performances signify better levels of thermal insulation. 


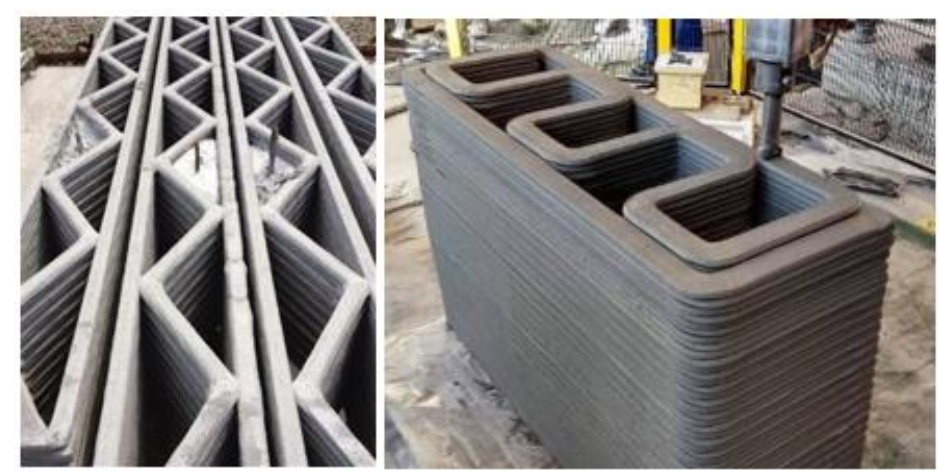

(a) (b)

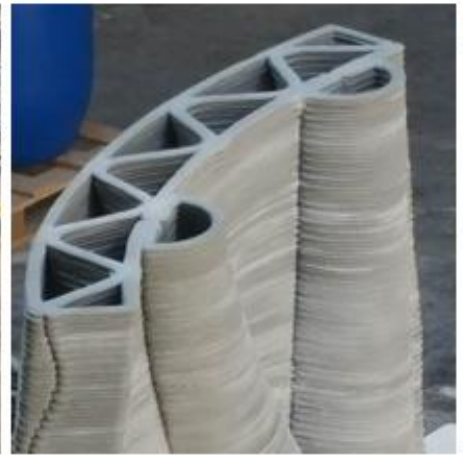

(c)

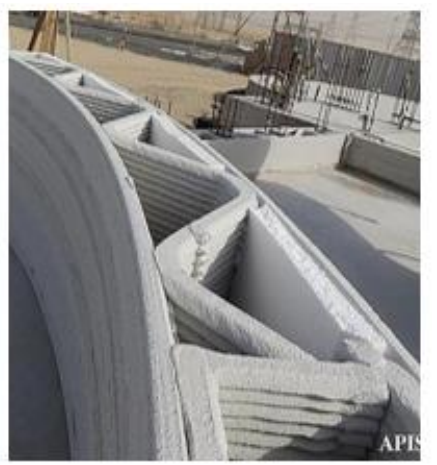

(d)

Figure 1. Examples of 3DPC wall panels with different cross-sectional arrangements: (a) triangular-shaped [25]; (b) latticeshaped 3DPC wall by ETESIAS [26]; (c) sinusoidal-shaped 3DPC wall by Gosselin et al. [27]; (d) sinusoidal shaped, from the world's largest 3DPC building in Dubai [28].

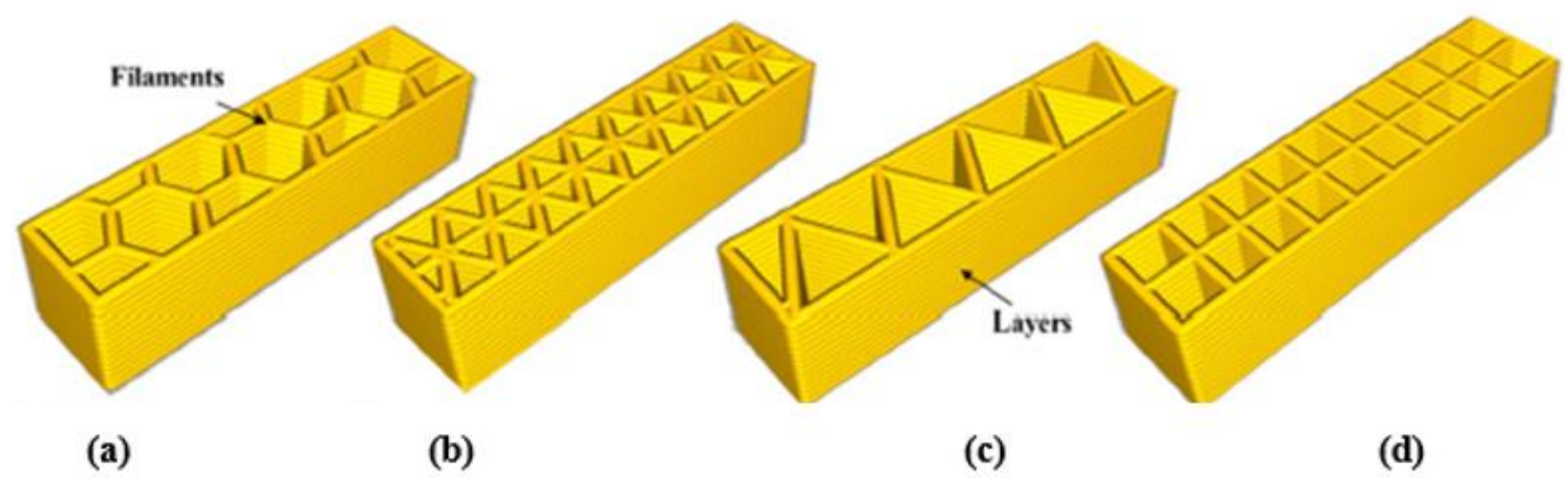

Figure 2. The different 3DPC cavity wall configurations studied by Wang et al. [24]: (a) cellular topology; (b) triangular topology; (c) truss topology; (d) lattice topology.

The ability to take precise measurements of the appropriate thermal performance is essential to understand and improve the thermal efficiency of this new 3DPC technology. The thermal performance of the exterior walls greatly influences the energy consumption of buildings and consequently their efficiency, as well as their emission of greenhouse gases $[2,29]$. In addition, the overall energy performance of a structure depends on external walls and their insulating value, and represents approximately $25 \%$ of the total heat loss [3]. The thermal performance, thickness, and properties of the materials used in these wall components play a significant role in regulating the heat loss and gain of the building $[2,23,30]$. The introduction of air gaps and filling the cavity using insulation materials or insulation layers between the structural elements is an effectual technique to attain the required thermal comfort of a building [31]. In addition, by enhancing the thermal insulating properties of the external walls, enhancements in construction sustainability can be also accomplished.

While energy-saving building features have been integrated into the design of 3DPC elements, there has not been a systematic study on the energy efficiency of 3DPC buildings. Pessoa et al. [29] conducted a systematic literature review to identify the key innovations made so far in 3DPC technology and its applicability in the construction industry, with specific attention being given to the thermal efficiency. Alkhalidi and Hatuqay [31] investigated and developed energy-efficient and low-cost residential 3DPC elements that could be accomplished through a green and sustainable method. Similarly, He et al. [32] introduced a 3DPC modular building system with an integrated vertical greenery system called the 3D-printed vertical green wall (3D-VtGW). Moreover, Craveiro et al. [33] experimentally analyzed the structural and thermal performances of several printable materials, including 
normal concrete, concrete mixed with cork, and concrete mix with expanded clay. Furthermore, Cuevas et al. [16] developed a 3D-printed lightweight concrete mixture with waste glass as an aggregate with lower density, and achieved a $40 \%$ reduction in thermal conductivity. Al-Ghamdi [7] conducted a detailed experimental study to examine the effects of different printing parameters to lower the energy consumption and printing period, and to ensure lightweight construction of acrylonitrile butadiene styrene (ABS) components through extrusion-based 3D printing. In addition, Marais et al. [30] numerically investigated the thermal performance of 3DPC structures with macrostructural cavity arrangements using lightweight foam concrete and high-performance concrete. However, there is still an obvious lack of investigations of the thermal energy performance of 3DPC structures to date, and there is a need to examine the thermal performance from a unique perspective.

\subsection{Scope of the Current Study}

In view of above discussion, the aim of the present study was to analyze the energy performance of 3DPC wall panels with different configurations and insulation materials. Complying with currently available geometries of 3DPC walls in the industry and the cavity arrangements proposed by Wang et al. [24], this study numerically investigated the energy performance of the innovative 3DPC wall configurations. Suitable heat transfer numerical models with cavity wall configurations proposed by Alkhalidi and Hatuqay [31] were developed using Abaqus [34] finite element software. The models were then validated by comparing the U-value results presented by Alkhalidi and Hatuqay [31]. The study was then extended with a detailed parametric study of 32 analyses by varying two different printing parameters, namely wall configurations and insulation material. The numerical analysis performed on the study revealed that the considered parameters had a significant influence on the energy efficiency of 3DPC wall panels. Finally, a suitable wall configuration with cavity insulation was proposed in order to ensure an energy-efficient and sustainable 3DPC wall panel development process. Furthermore, using the numerical analysis, a simple equation was also derived to determine the U-value of complex cavity geometries without using FE modelling. This study offers a vision to the future investigation of energy-efficient, complex 3DPC structures that can be utilized in the construction industry.

\section{Development of the Finite Element Model}

This section explains the development of the three-dimensional finite element (FE) model for analysing the energy performance of 3DPC wall panels with different crosssectional arrangements. The U-value is the thermal transmittance of the wall configuration. It has a direct relationship with the element's thermal performance; if the U-value is low, it implies that the wall's thermal performance is better. U-value $(\mathrm{U})$ has an inverse relationship with thermal resistance $\left(R_{\mathrm{T}}\right)$ of the element (Equation (1)). The thermal resistance of the element depends on the internal surface thermal resistance $\left(R_{\mathrm{si}}\right)$, external surface thermal resistance $\left(R_{\mathrm{se}}\right)$, and the element layer resistance $(R)$ (Equation (2)). Further heat flux and the temperature variation between the external and internal surfaces has a relationship with the U-value (Equation (3)). Thermal resistance has a co-relationship with the thermal conductivity $(\lambda)$ and the thickness of the layer $(d)$ as expressed in Equation (4). If a wall configuration is available with different layers of materials using Equation (2), the U-value of the wall configuration could be easily determined. However, instead of layers, the combination of materials was in complex shapes in the 3DPC wall configurations considered in this study, and thus a direct equation could not be used. Therefore, a numerical analysis was utilized in determining the U-values of the analysed wall configurations.

$$
\begin{gathered}
\mathrm{U}=\frac{1}{R_{\mathrm{T}}} \\
R_{\mathrm{T}}=R_{\mathrm{si}}+R+R_{\mathrm{se}} \\
\text { Heat Flux }=\text { Temperature Difference } \times(\mathrm{U}-\text { Value })
\end{gathered}
$$




$$
R=\frac{d}{\lambda}
$$

The examination of overall thermal performance of a structure is known as coupled analysis, which investigates the combined mechanical-thermal behaviour. Due to the lack of experimental investigations, non-load-bearing 3DPC wall configurations were considered in this study, and uncoupled heat-transfer analysis was performed. Hence, the developed models were incapable of simulating the structural behaviour or the fracture of the wall. Therefore, three-dimensional heat-transfer analysis was conducted to determine the 3DPC wall configurations' thermal transmittance; the steady-state heat transfer depended on the thermal conductivity of the material. The thermal conductivities of the concrete mixture used for the 3DPC cavity wall panels and the cavity insulation material, expanded polylactic acid (E-PLA), were obtained from the study performed by Alkhalidi and Hatuqay [31]. External and internal temperature boundary conditions were set to $0{ }^{\circ} \mathrm{C}$ and $40^{\circ} \mathrm{C}$, respectively. The convective surface heat-transfer coefficients were set according to EN ISO 6946: $25 \mathrm{~W} \cdot \mathrm{m}^{-2} \cdot \mathrm{K}^{-1}$ and $7.69 \mathrm{~W} \cdot \mathrm{m}^{-2} \cdot \mathrm{K}^{-1}$ for the external and internal environment, respectively. Two surface film condition interactions were defined separately in the external and internal surfaces to achieve these boundary conditions in the developed FE model. For the external surface film, a coefficient of $25 \mathrm{~W} \cdot \mathrm{m}^{-2} \cdot \mathrm{K}^{-1}$ was set with a sink temperature of $0{ }^{\circ} \mathrm{C}$; whereas for the internal surface film, a coefficient of $7.69 \mathrm{~W} \cdot \mathrm{m}^{-2} \cdot \mathrm{K}^{-1}$ was set with a sink temperature of $40^{\circ} \mathrm{C}$. Heat-transfer elements (DC3D8 elements) were used in meshing the model. Global seeding of $10 \mathrm{~mm}$ and edge seeding of $2 \mathrm{~mm}$ was achieved through the thickness as mesh sizes, and steady-state heat-transfer analysis was conducted. Heat-flux results were obtained as a result of the analysis, and based on the Equation (3), U-values were calculated, dividing the average heat flux from the temperature difference $\left(40^{\circ} \mathrm{C}\right)$. The cavity of the configurations was modelled as air layers. Air thermal transmittance was considered as $0.18 \mathrm{~m}^{2} \cdot \mathrm{K} / \mathrm{W}$, and considering the relationship given in Equation (4), air thermal conductivity $(\lambda c)$ was calculated based on the thickness of the air layer. The geometry modelling, applying boundary conditions, applying tie constraints, and meshing of one of the wall configurations, are shown in Figure 3a-c.

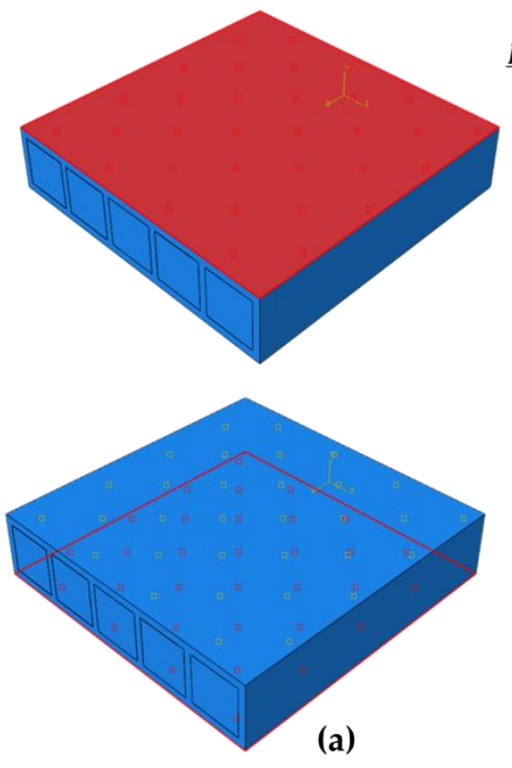

\section{External Surface Film condition Film Coef ficient : $25 \mathrm{Wm}^{-2} \mathrm{~K}^{-1}$ Sink Temperature: $0^{0} \mathrm{C}$}

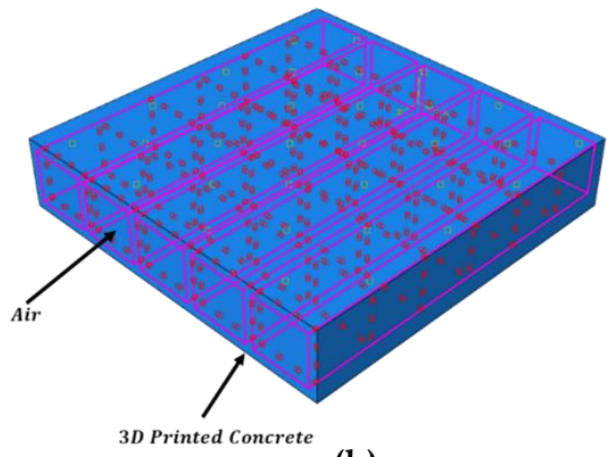

(b)

Internal Surface Film condition Film Coefficient : $7.69 \mathrm{Wm}^{-2} \mathrm{~K}^{-1}$ Sink Temperature: $40^{\circ} \mathrm{C}$

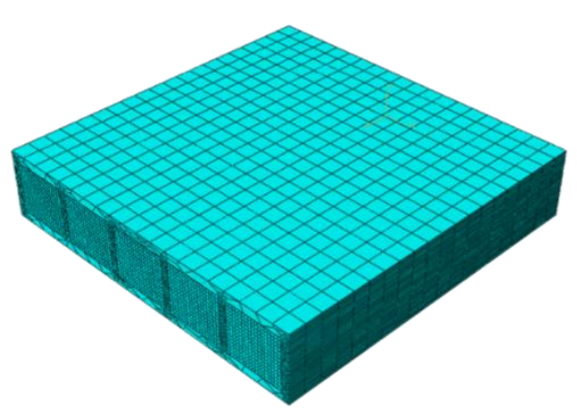

(c)

Figure 3. (a) Geometry and boundary conditions; (b) tie constraints; (c) meshing. 


\section{Validation of the Developed FE Model}

Validation of the developed simulation was essential to evaluate the accuracy of the implemented models, the assumed simplifications for the model applications, and the material characterization. Hence, all developed simulation models were validated against previously published literature. The U-values results obtained from the finite element analysis (FEA) using Abaqus were compared with the results presented by Alkhalidi and Hatuqay [31], who calculated the U-value of the wall configurations with air gap and cavity filled with expanded polylactic acid (E-PLA). Five different 3DPC wall arrangements with three different materials were used in this study. Hence, 30 models were validated in total. Three material mixes were selected with recyclable contents with excellent thermal properties. The first tested mix was a sulphur concrete mix, the second was a cork concrete, and the third was composed of powdered silica sand with an organic binder. The thermal properties of the concrete mixes are presented in Table 1, and the thermophysical properties of air and E-PLA are given in Table 2. The wall panel arrangements used for the validation are illustrated in Figure 4.

Table 1. Properties of the concrete mix [31].

\begin{tabular}{ccccc}
\hline Mix & Density $\left(\mathbf{k g} / \mathbf{m}^{\mathbf{3}}\right)$ & $\begin{array}{c}\text { Thermal Conductivity } \\
(\mathbf{W} / \mathbf{m} \cdot \mathbf{K})\end{array}$ & $\begin{array}{c}\text { Specific Heat } \\
(\mathbf{J} / \mathbf{g} \cdot \mathbf{K})\end{array}$ & Emissivity \\
\hline Mix 1 & 1254 & 0.367 & 0.803 & 0.558 \\
Mix 2 & 986 & 0.338 & 1.127 & 0.583 \\
Mix 3 & 1522 & 0.2 & 0.73 & 0.94 \\
\hline
\end{tabular}

Table 2. Thermophysical properties of the cavity insulation [31].

\begin{tabular}{ccccc}
\hline $\begin{array}{c}\text { Cavity } \\
\text { Filling }\end{array}$ & Density $\left(\mathbf{k g} / \mathbf{m}^{\mathbf{3}}\right)$ & $\begin{array}{c}\text { Thermal Conductivity } \\
(\mathbf{W} / \mathbf{m} \cdot \mathbf{K})\end{array}$ & $\begin{array}{c}\text { Specific Heat } \\
\mathbf{( J / g} \cdot \mathbf{K})\end{array}$ & $\begin{array}{c}\text { Viscosity } \\
\mathbf{( k g / m} \cdot \mathbf{s})\end{array}$ \\
\hline Air cavity & Ideal gas & 0.0242 & 1.00643 & $1.7894 \times 10^{-5}$ \\
E-PLA & 30 & 0.03 & 1.483 & - \\
\hline
\end{tabular}

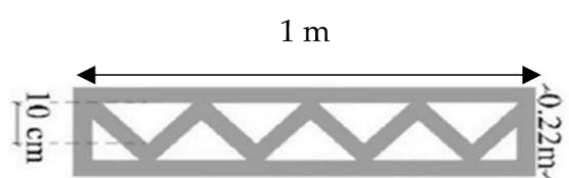

(a)

$1 \mathrm{~m}$

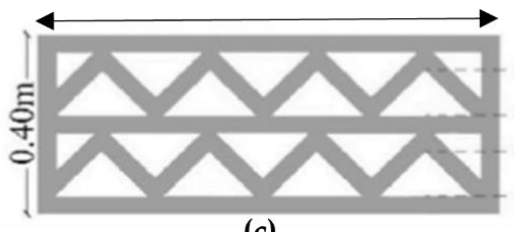

(c)

$1 \mathrm{~m}$

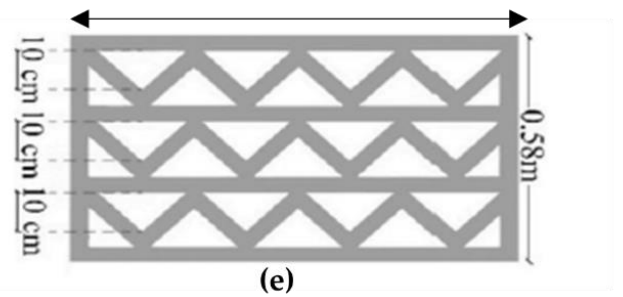

$1 \mathrm{~m}$

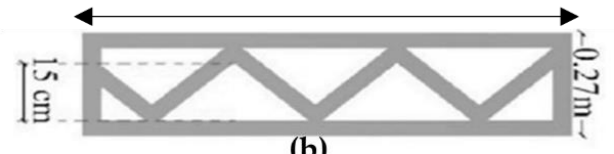

(b)

$1 \mathrm{~m}$

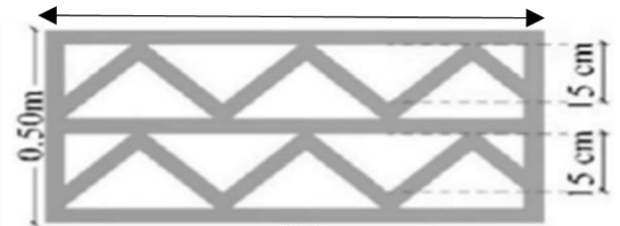

(d)

Figure 4. Wall configurations proposed by Alkhalidi and Hatuqay [31]: (a) single row, $10 \mathrm{~cm}$ (W1); (b) single row, $15 \mathrm{~cm}$ (W2); (c) double row, $10 \mathrm{~cm}$ (W3); (d) double row, $15 \mathrm{~cm}$ (W4); (e) triple row, $10 \mathrm{~cm}$ (W5). 
The comparison of results of three different mixes (Mix 1, Mix 2, and Mix 3) of 3DPC are shown in Figure $5 \mathrm{a}-\mathrm{c}$. The U-value curves of wall configurations presented by Alkhalidi and Hatuqay [31] showed excellent agreement with the FEA results, hence the Abaqus simulations were accurate and reliable. Since the U-values results matched, we concluded that the developed FE models could be utilized for detailed parametric analysis of the energy performance of 3DPC walls.

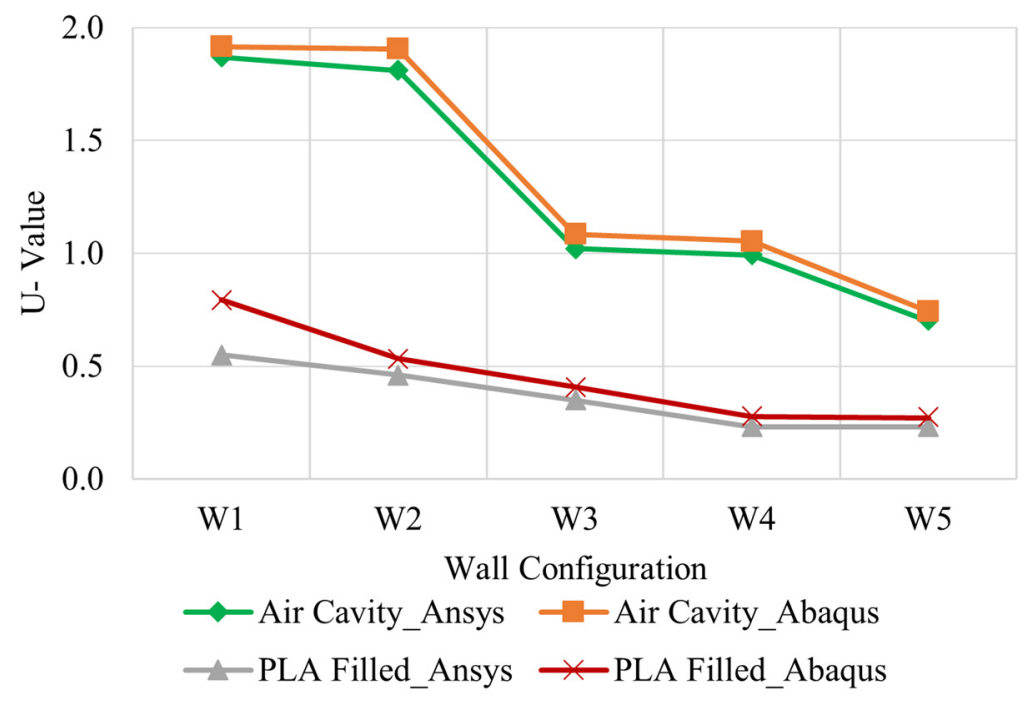

(a)

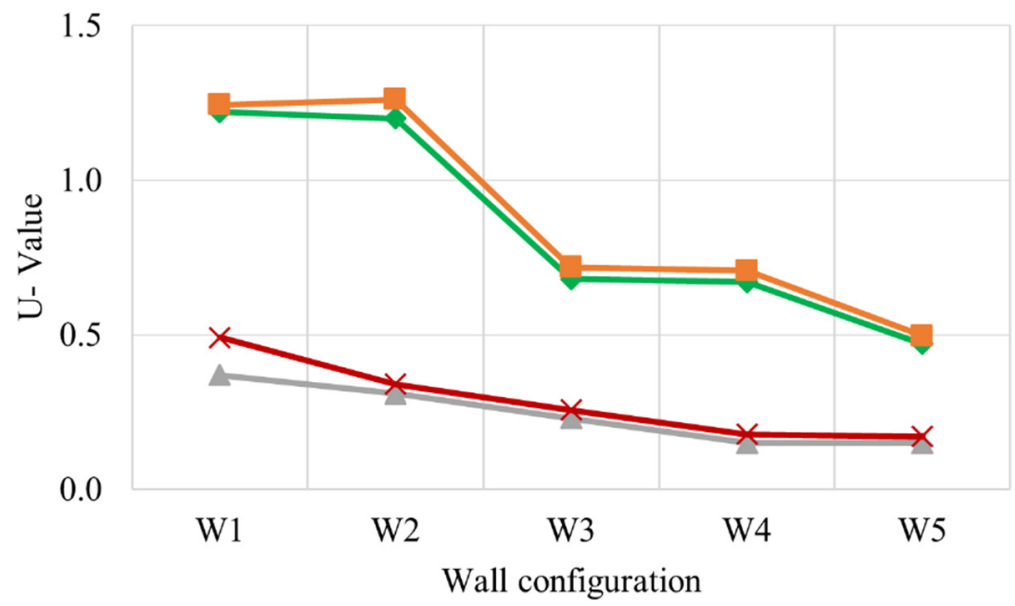

$$
\begin{aligned}
& \multimap \text { Air Cavity_Ansys }- \text { Air Cavity_Abaqus } \\
& \leftarrow \text { PLA Filled_Ansys } \leftarrow \text { PLA Filled_Abaqus }
\end{aligned}
$$

(b)

Figure 5. Cont. 


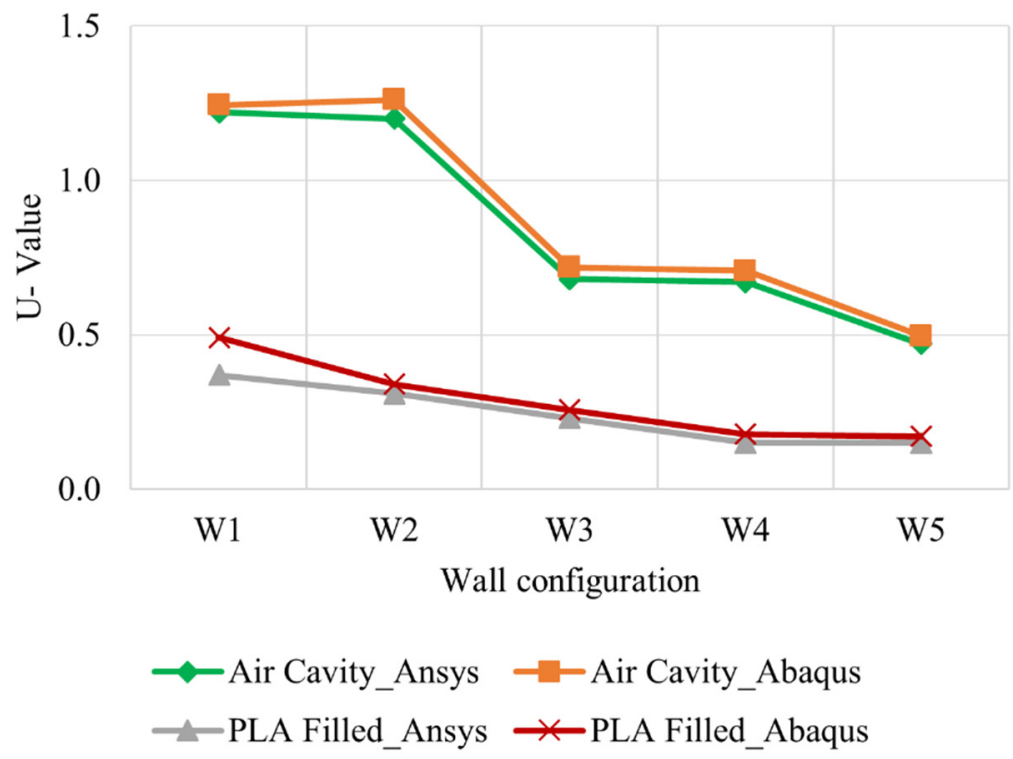

(c)

Figure 5. (a) Concrete Mix 1 U-value comparison; (b) concrete Mix 2 U-value comparison; (c) concrete Mix 3 U-value comparison.

\section{Parametric Study}

Currently, 3D-printed solid wall panels with different thicknesses are used in industry for improved thermal and acoustic characteristics. When the increasing wall thickness, energy, and acoustic performance are enhanced, however, material costs and carbon footprint are increased. The most crucial problem with wide concrete wall panels is the challenging nature of handling the panels at the construction site, due to their heavy weight. Complying with currently available 3DPC wall panels in the industry and the wall configurations proposed by Wang et al. [24], eight (8) innovative cavity wall configurations were chosen to observe the effect of thickness of the wall panels, cross-sectional configurations, and the thermal insulation on the energy performance. Mix 3 from the study by Alkhalidi and Hatuqay [31] was selected for this parametric study due to its better energy performance with lower U-values; the properties of this printable concrete are presented in Table 1. In this study, a heat-transfer analysis was conducted on wall panels with thicknesses of $100 \mathrm{~mm}$ and $12 \mathrm{~mm}$ layer thickness, and wall thicknesses of $200 \mathrm{~mm}$ with $25 \mathrm{~mm}$ layer thickness. The nozzle sizes were selected based on the actual constructed structures. The walls were developed to be $1 \mathrm{~m}$ long and $1 \mathrm{~m}$ high with different cross-sectional arrangements. The parametric study included 32 wall specimens of eight different single- and double-row cross-sectional arrangements, with and without cavity insulation. The details of the parametric study are presented in Table 3. The analysed different configurations details are shown in Table 4 . The same wall panels also were analysed with E-PLA cavity insulation.

Table 3. Outline of the parametric study.

\begin{tabular}{|c|c|c|c|}
\hline Wall Thickness & Wall Configuration & Insulation Type & Number of Models \\
\hline & C1 & & 4 \\
\hline & $\mathrm{C} 2$ & & 4 \\
\hline & C3 & & 4 \\
\hline $100 \mathrm{~mm}$ & C4 & Air cavity & 4 \\
\hline $200 \mathrm{~mm}$ & C5 & E-PLA insulation & 4 \\
\hline & C6 & & 4 \\
\hline & C7 & & 4 \\
\hline & $\mathrm{C} 8$ & & 4 \\
\hline Total & & & 32 \\
\hline
\end{tabular}


Table 4. Different cross-sectioned 3DPC wall configurations.

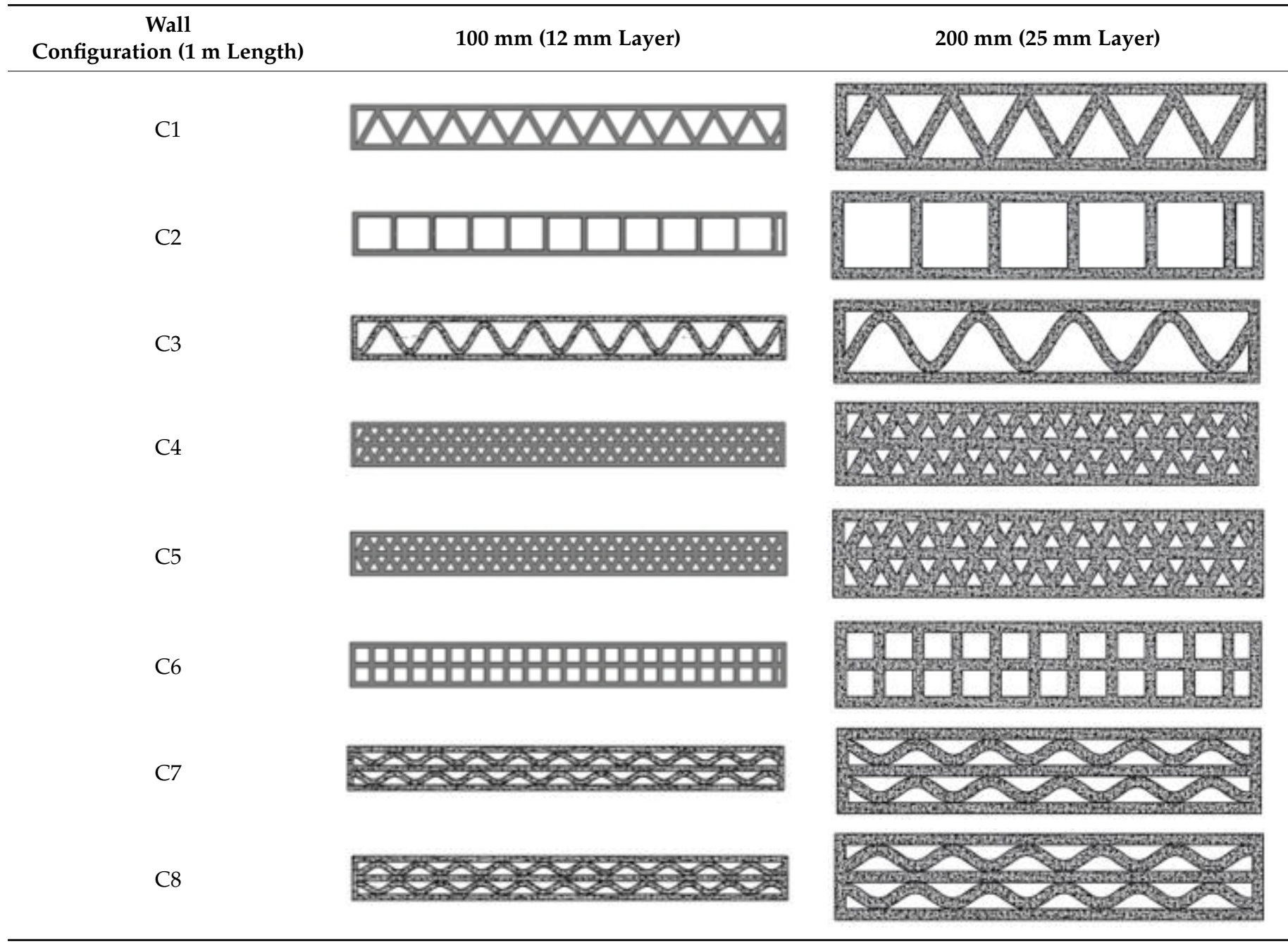

\section{Results and Discussion}

This section describes the numerical simulation results derived for the considered wall configurations for energy performance and the variation of thermal transmittance value (U-values). The measured U-values of each wall configuration is given in Table 5. The effect of wall thickness and the cross-sectional configurations with the void area are discussed extensively herein.

\subsection{Effect of Wall Thickness with Different Configurations}

Figure 6 shows the variation of U-value for the considered $100 \mathrm{~mm}$ and $200 \mathrm{~mm}$ thickness wall configurations without cavity insulation. It is clear that the U-value mostly decreased with increased wall thickness regardless of the cross-sectional configurations, except the double-row lattice configuration $\left(\mathrm{C}_{200}\right)$. Moreover, $\mathrm{C} 1, \mathrm{C} 2$, and $\mathrm{C} 3$ were developed with single-row cross-sectional configurations, and the $\mathrm{C} 4-\mathrm{C} 8$ wall panels were developed with double rows (Table 4). Hence, a significant reduction in the U-value was identified for the $100 \mathrm{~mm}$ double-row wall panels compared to the single-row panels. However, there was a fluctuating trend identified for the $200 \mathrm{~mm}$ wall configurations.

In terms of different cross-sectional configurations, higher intermediate barriers caused a reduction in material conductivities; hence, an increased thermal efficiency was obtained. In both single- and double-row $100 \mathrm{~mm}$ breadth wall panels, the triangular shaped panels displayed a higher performance, with lower U-values compared to other configurations. However, lattice-shaped wall panels showed a higher reduction in the U-value of approxi- 
mately $40 \%$ when increasing the midway partitions with an additional row. The $200 \mathrm{~mm}$ thickness wall panels with triangular and sinusoidal shapes also showed a similar percentage of reduction, whereas the lattice-shaped wall panels behaved contrarily. The reduction in U-values due to increasing intermediate barriers with an additional row is listed in Table 6. However, these values derived for thermal transmittance were considerably higher than the required standard values. Hence, expanded polylactic acid (E-PLA) was used as thermal insulation material, and the U-values were assessed again. E-PLA is a lightweight sustainable material that has similar properties to expanded polystyrene.

Table 5. The U-values derived from the FE analysis.

\begin{tabular}{|c|c|c|c|c|}
\hline \multirow{2}{*}{$\begin{array}{c}\text { Wall } \\
\text { Configuration }\end{array}$} & \multirow{2}{*}{$\begin{array}{l}\text { Cavity Area } \\
\qquad\left(\mathrm{mm}^{2}\right)\end{array}$} & \multirow{2}{*}{$\begin{array}{c}\text { Concrete Area } \\
\left(\mathrm{mm}^{2}\right)\end{array}$} & \multicolumn{2}{|r|}{ U-Values } \\
\hline & & & Cavity Wall & E-PLA Insulated Wall \\
\hline $\mathrm{C} 1_{100}$ & 52,519 & 47,481 & 2.68 & 0.87 \\
\hline $\mathrm{C} 2100$ & 64,144 & 35,856 & 3.16 & 0.65 \\
\hline C 3100 & 57,174 & 42,826 & 2.79 & 0.64 \\
\hline $\mathrm{C} 4_{100}$ & 23,923 & 76,077 & 1.85 & 1.42 \\
\hline $\mathrm{C} 5_{100}$ & 23,923 & 76,077 & 1.85 & 1.42 \\
\hline C6 6100 & 45,568 & 54,432 & 1.89 & 0.96 \\
\hline $\mathrm{C} 7100$ & 37,736 & 62,264 & 2.09 & 0.68 \\
\hline $\mathrm{C} 8100$ & 37,736 & 62,264 & 2.09 & 0.69 \\
\hline $\mathrm{Cl}_{200}$ & 99,330 & 100,670 & 1.74 & 0.45 \\
\hline $\mathrm{C} 2200$ & 126,225 & 73,775 & 1.26 & 0.50 \\
\hline $\mathrm{C} 3_{200}$ & 106,855 & 93,145 & 1.71 & 0.49 \\
\hline $\mathrm{C} 4_{200}$ & 43,477 & 156,523 & 1.01 & 0.73 \\
\hline $\mathrm{C} 5200$ & 43,477 & 156,523 & 1.01 & 0.72 \\
\hline $\mathrm{C} 6200$ & 87,500 & 112,500 & 2.17 & 0.34 \\
\hline $\mathrm{C} 7200$ & 72,721 & 127,279 & 1.01 & 0.49 \\
\hline $\mathrm{C} 8200$ & 72,721 & 127,279 & 1.01 & 0.50 \\
\hline
\end{tabular}

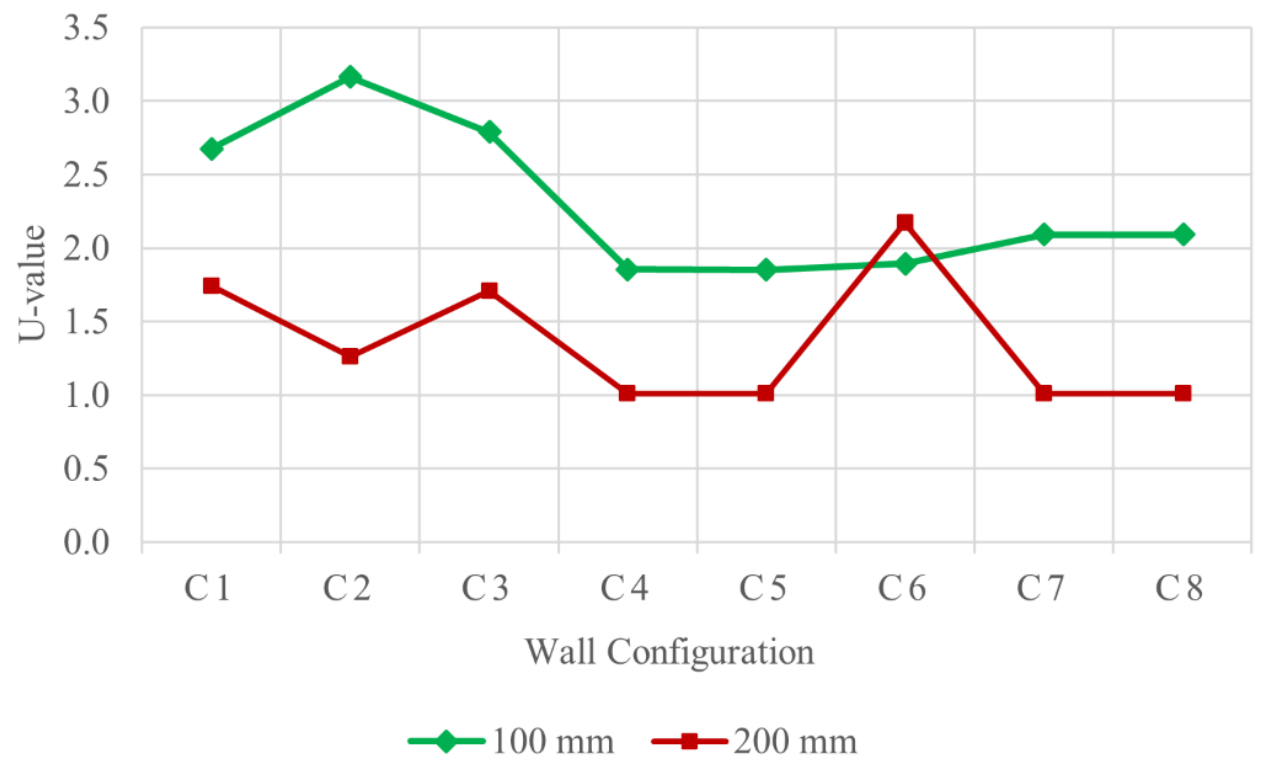

Figure 6. The U-value results obtained for different wall configurations with different wall thickness.

Table 6. The U-value reduction percentages.

\begin{tabular}{ccc}
\hline \multirow{2}{*}{ Wall Arrangement } & \multicolumn{2}{c}{ U-Value Reduction Percentage for Double Rows (\%) } \\
\cline { 2 - 3 } & $\mathbf{1 0 0} \mathbf{~} \mathbf{m}$ Wall & $\mathbf{2 0 0} \mathbf{~ m m ~ W a l l}$ \\
\hline Triangular & 30.71 & 42.10 \\
Lattice & 40.13 & -42.03 \\
Sinusoid & 25.02 & 40.72 \\
\hline
\end{tabular}




\subsection{Effect of Cavity Insulation}

Figure 7 illustrates the U-values obtained from the analysis for the selected $100 \mathrm{~mm}$ wall configurations with and without cavity insulation. The incorporation of E-PLA material as the insulation reduced the U-value, and thus increased the thermal performance of the wall panels for all the configurations. However, single-row wall configurations achieved relatively higher reductions in U-value compared to some of the double row wall configurations which contradicted the results presented by Alkhalidi and Hatuqay [31]. Hence, there was an obvious relationship for U-values with the volume of the cavity and insulation, which must be examined further.
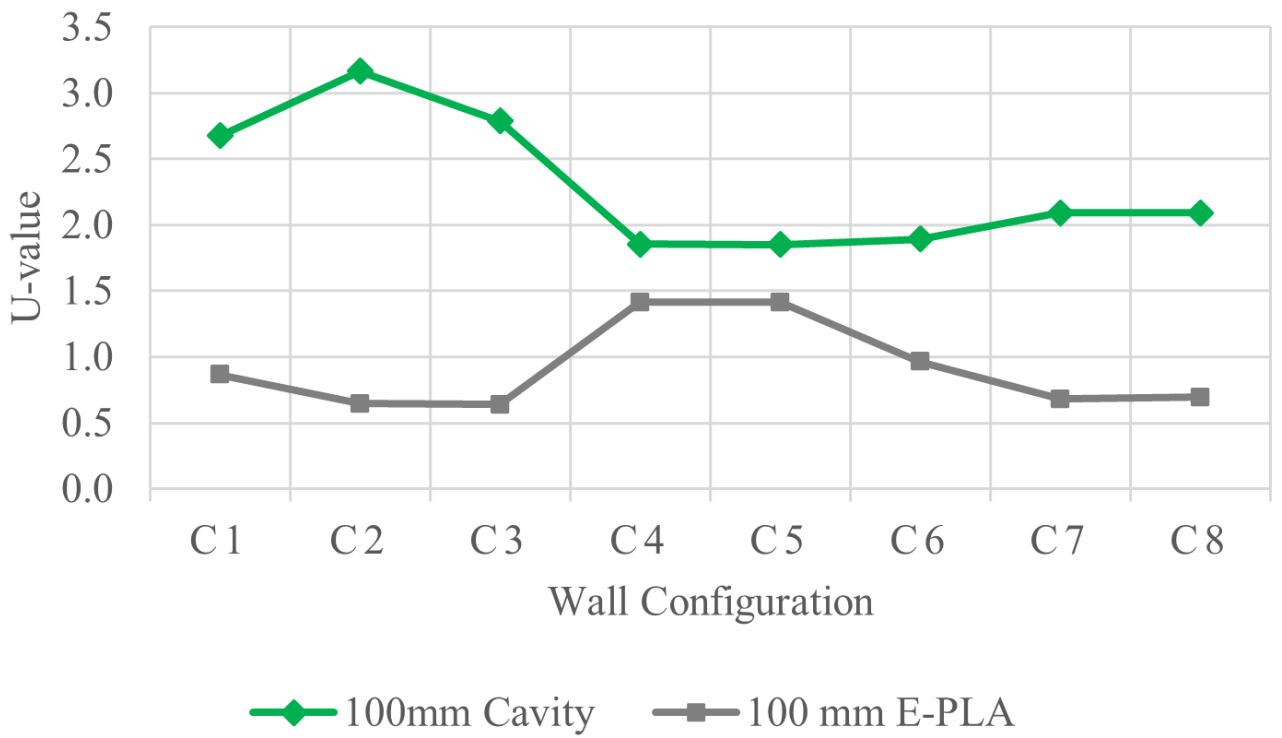

Figure 7. The U-value results obtained for $100 \mathrm{~mm}$ wall configurations with and without cavity insulation.

In relation to the cross-sectional arrangements, single-row lattice and sinusoid and double-row sinusoidal arrangements exhibited a higher energy performance, while those filled with E-PLA had U-values in the range of $0.64-0.69 \mathrm{~W} / \mathrm{m}^{2} \cdot \mathrm{K}$. Conversely, triangularshaped wall panels showed a relatively lower performance with an increased midway row. The reductions in U-values due to the incorporation of insulation material is presented in Table 7. Still, these values of thermal transmittance were noticeably higher than the required standard values. Hence, the $200 \mathrm{~mm}$ thickness wall panels were examined to further reduce the U-values while increasing the performance.

Figure 8 depicts the U-value results derived for $200 \mathrm{~mm}$ wall configurations with and without E-PLA insulation. The cavity insulation with E-PLA material had significantly reduced U-values. Moreover, approximately similar U-values were attained for all the wall configurations irrespective of single- and double-row arrangements. This scenario must be further investigated with respect to cavity volume.

From Figure 8, it is apparent that the wall with double-row lattice arrangement had a lower U-value of $0.34 \mathrm{~W} / \mathrm{m}^{2} \cdot \mathrm{K}$ with E-PLA insulation. All three single-row wall configurations and double-row sinusoidal arrangements also showed better energy performance when filled with E-PLA, with U-values in the range of $0.45-0.50 \mathrm{~W} / \mathrm{m}^{2} \cdot \mathrm{K}$. Similar to $100 \mathrm{~mm}$ wall panels, double-row, triangular-shaped wall panels showed a comparatively lower performance with increased intermediate barriers. Furthermore, Figure 9 shows the variation in U-values for all the wall panels studied with and without cavity insulation. An evident reduction in U-values was observed with cavity insulation for both the $100 \mathrm{~mm}$ and $200 \mathrm{~mm}$ thickness wall panels. Moreover, $100 \mathrm{~mm}$ wall panels with E-PLA exhibited lower U-values compared to $200 \mathrm{~mm}$ cavity walls, except both double-row triangular 
cross-sectional wall panels. However, the U-values were nearly identical for single-row wall configurations and the double-row sine-curved wall panels regardless of the wall thickness when cavity-insulated. The reduction percentages of the U-values due to the incorporation of insulation material are presented in Table 7.

Table 7. The U-value reduction percentages (\%) with insulation.

\begin{tabular}{cccc}
\hline Wall Configuration & $\begin{array}{c}\text { U-Value Reduction } \\
\text { Percentage (\%) }\end{array}$ & Wall Configuration & $\begin{array}{c}\text { U-Value Reduction } \\
\text { Percentage (\%) }\end{array}$ \\
\hline $\mathrm{C1}_{100}$ & 67.67 & $\mathrm{C1}_{200}$ & 74.20 \\
$\mathrm{C} 2_{100}$ & 79.59 & $\mathrm{C} 200$ & 60.50 \\
$\mathrm{C} 3_{100}$ & 77.09 & $\mathrm{C}_{200}$ & 71.38 \\
$\mathrm{C} 4_{100}$ & 23.62 & $\mathrm{C}_{200}$ & 27.64 \\
$\mathrm{C} 5_{100}$ & 23.61 & $\mathrm{C}_{200}$ & 28.23 \\
$\mathrm{C} 6_{100}$ & 49.22 & $\mathrm{C}_{200}$ & 84.29 \\
$\mathrm{C} 7_{100}$ & 67.51 & $\mathrm{C} 7_{200}$ & 51.51 \\
$\mathrm{C} 8_{100}$ & 66.88 & $\mathrm{C}_{200}$ & 50.49 \\
\hline
\end{tabular}

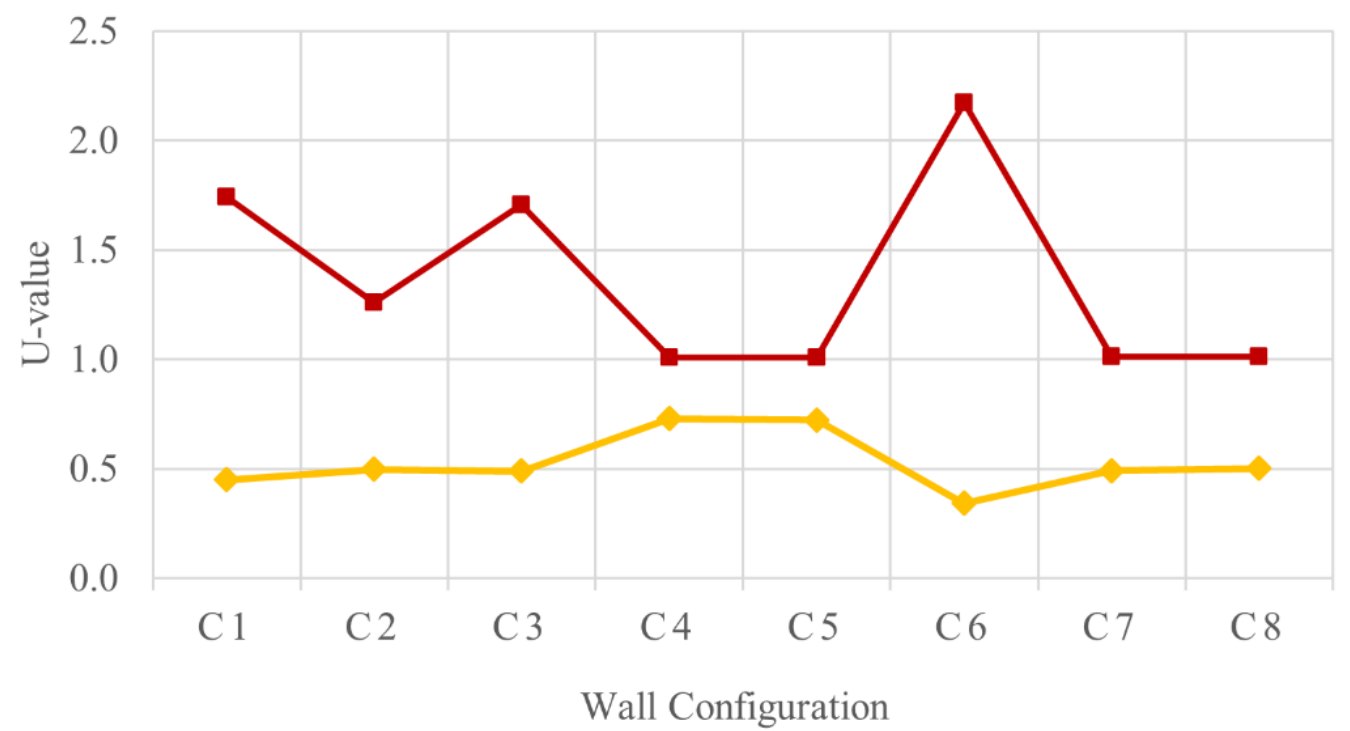

$\rightarrow-200$ mm Cavity $\quad \longrightarrow 200 \mathrm{~mm}$ E-PLA

Figure 8. The U-value results obtained for $200 \mathrm{~mm}$ wall configurations with and without cavity insulation.

Wall configurations with double-row triangular arrangements did not attain a noticeable reduction in U-values with the integration of E-PLA insulation. Observed reductions in U-values were nearly $23 \%$ and $28 \%$ for $100 \mathrm{~mm}$ and $200 \mathrm{~mm}$ wall panels, respectively. However, all the other wall configurations attained a significant improvement in energy performance with E-PLA insulation. The measured reduction in U-values for the single-row triangular, lattice, and sinusoid wall arrangements with insulation ranged around $60-70 \%$, which clearly showed the connectivity with the void area and energy performance with the integration of insulation material. In addition, the $\mathrm{C}_{200}$ (double-row lattice arrangement), which had the highest $\mathrm{U}$-value of $2.17 \mathrm{~W} / \mathrm{m}^{2} \cdot \mathrm{K}$. among the $200 \mathrm{~mm}$ wall panels, achieved a lower U-value of $0.34 \mathrm{~W} / \mathrm{m}^{2} \cdot \mathrm{K}$ with E-PLA insulation, with higher performance compared to all the other configurations. Hence, the variation of U-value with the void area was studied to further understand the behaviour of the considered wall configurations. Since the thermal conductivity of void air changes with the thickness, only the variation in U-values with E-PLA insulation was investigated. 


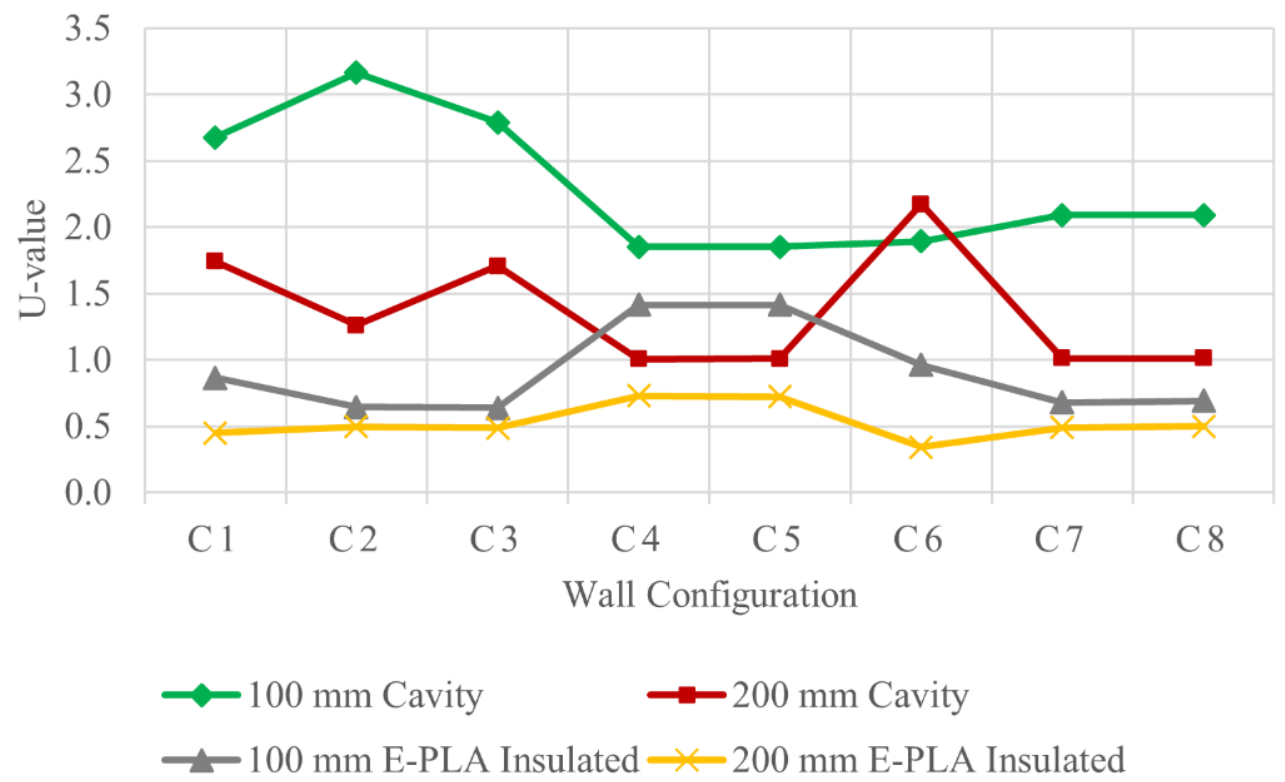

Figure 9. The U-value results obtained for $100 \mathrm{~mm}$ and $200 \mathrm{~mm}$ wall configurations with and without cavity insulation.

\subsection{Variation of U-Values with Cavity Area}

As shown in Figure 10, the U-value was relatively decreased with an increased void area with insulation. A larger amount of insulation directed a reduction in material conductivities; hence, the best thermal efficiency was achieved. However, with the different cross-sectional arrangements and variations in thermal transmittance path, fluctuating behaviour was identified. However, the $200 \mathrm{~mm}$ wall panels, such as single-row triangular $\left(\mathrm{C}_{200}\right)$, lattice $\left(\mathrm{C}_{200}\right)$, sinusoid $\left(\mathrm{C}_{200}\right)$, and double-row lattice $\left(\mathrm{C}_{200}\right)$ and sinusoid $\left(\mathrm{C}_{200}\right.$, $\mathrm{C}^{18}{ }_{200}$ ) showed improved performances with E-PLA insulation. Figures 11 and 12 display the heat-flux variation along the wall panels for $100 \mathrm{~mm}$ and $200 \mathrm{~mm}$, respectively.

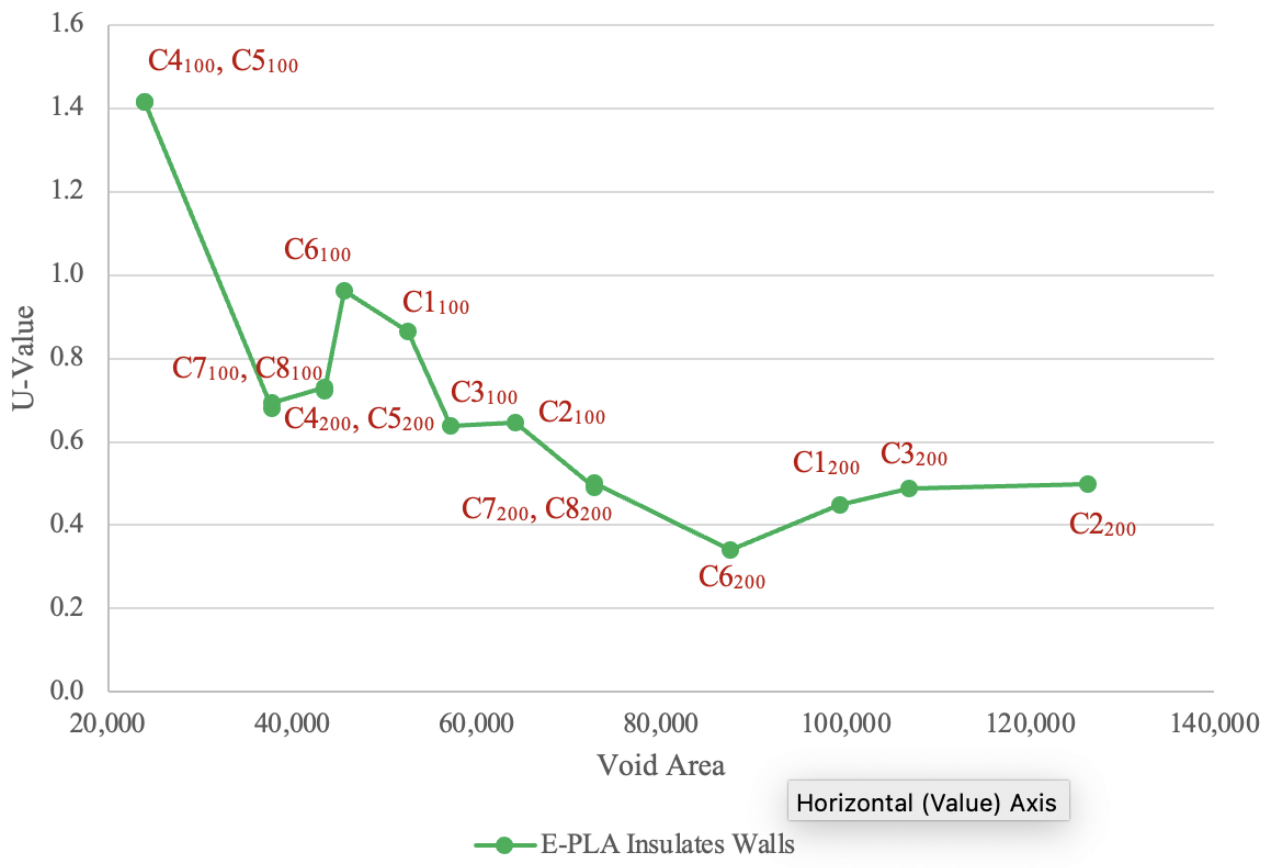

Figure 10. The U-value variation with cavity area. 


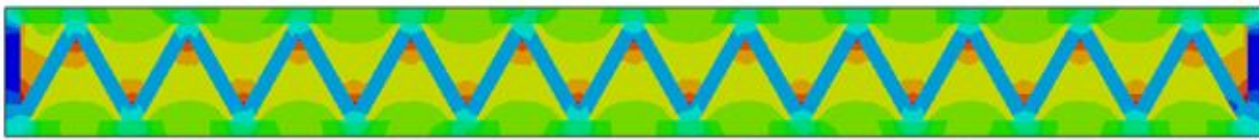

(a) Cavity wall $\mathrm{C1}_{100}$
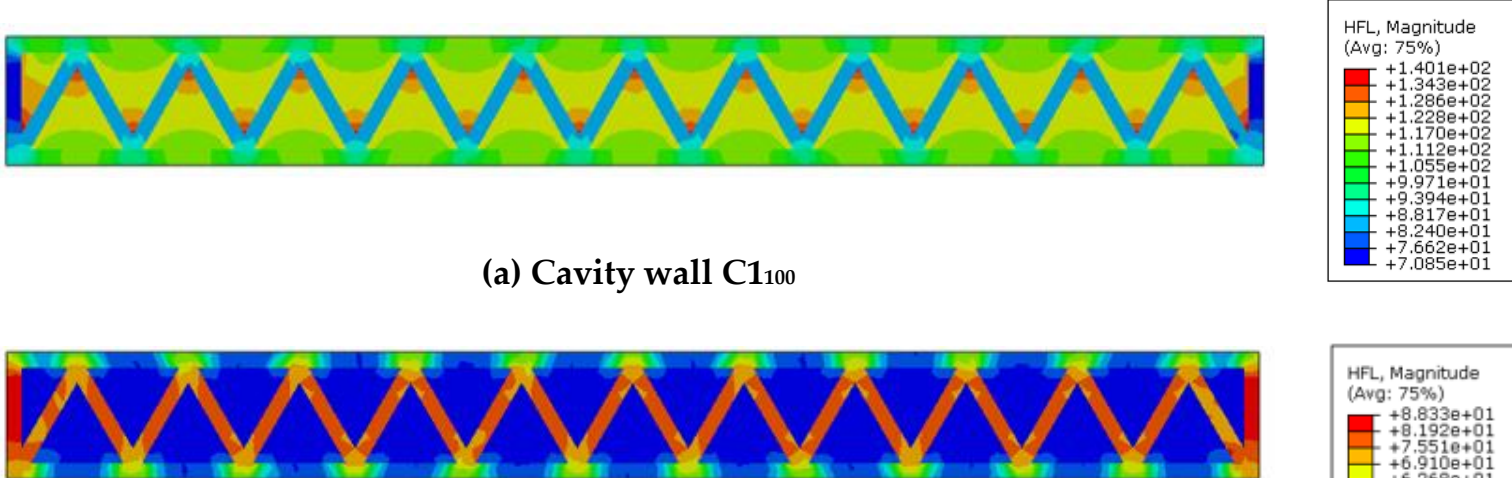

(b) E-PLA cavity insulated wall C1100
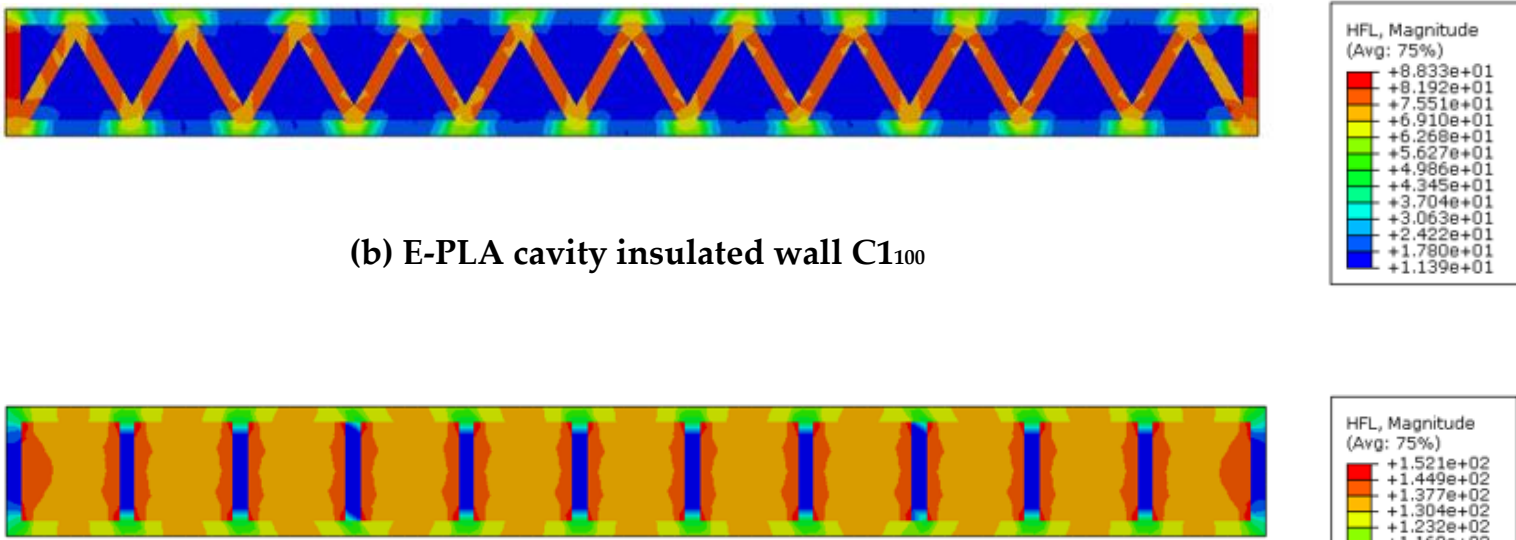

(a) Cavity wall C2100
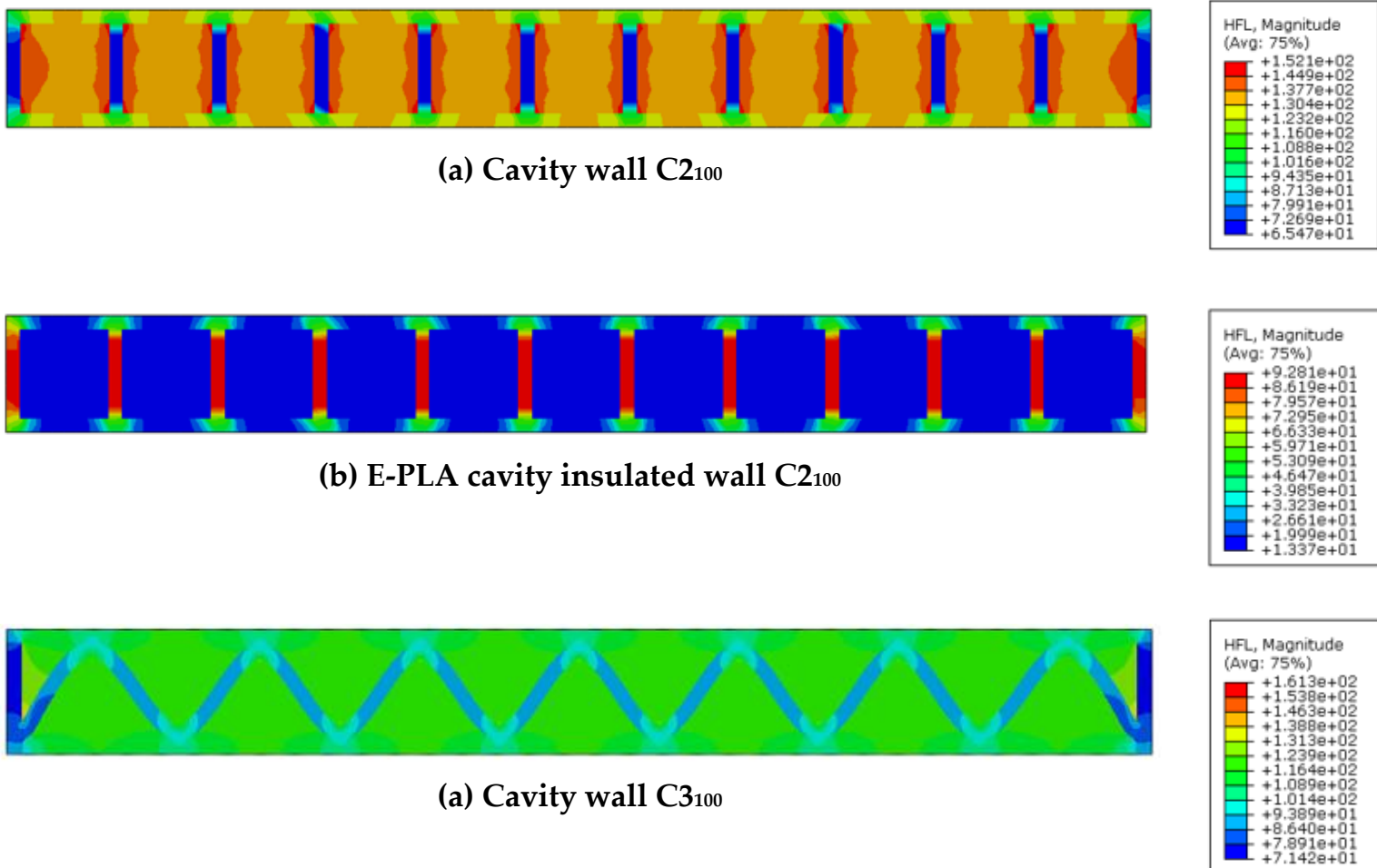

(a) Cavity wall C3100
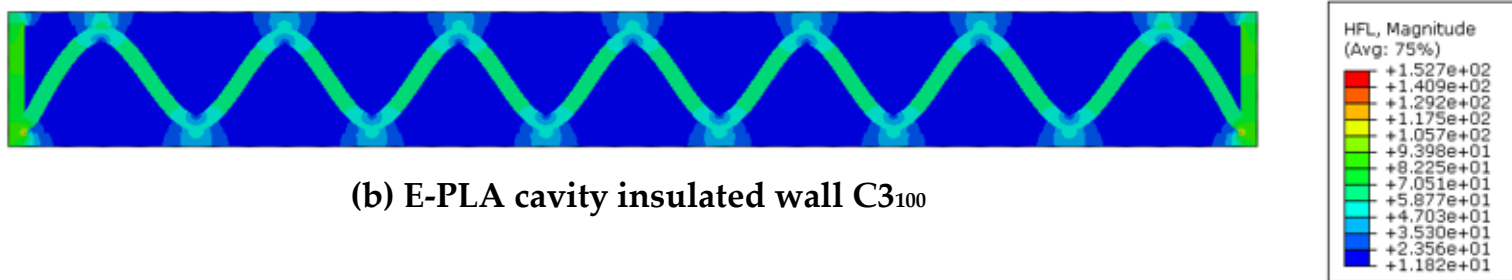

Figure 11. Cont. 


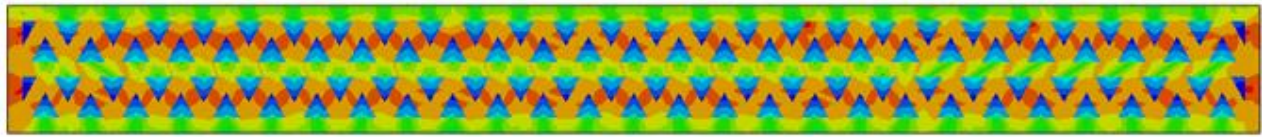

(a) Cavity wall C4100

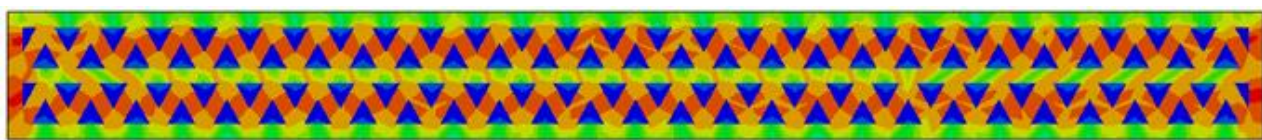

(b) E-PLA cavity insulated wall C4100

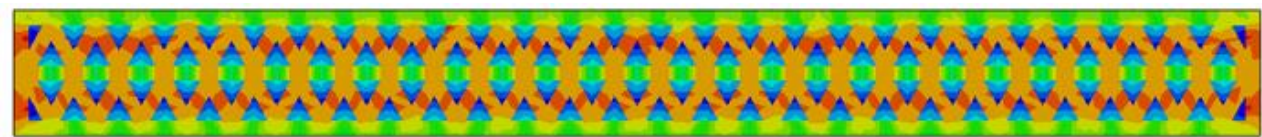

(a) Cavity wall C5100

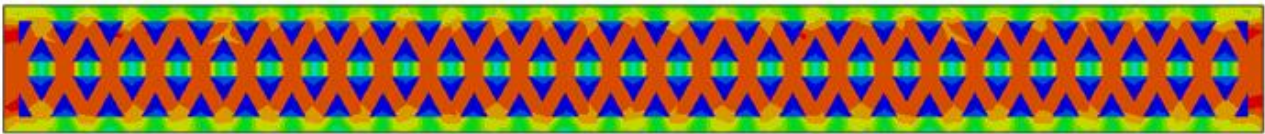

(b) E-PLA cavity insulated wall C5100
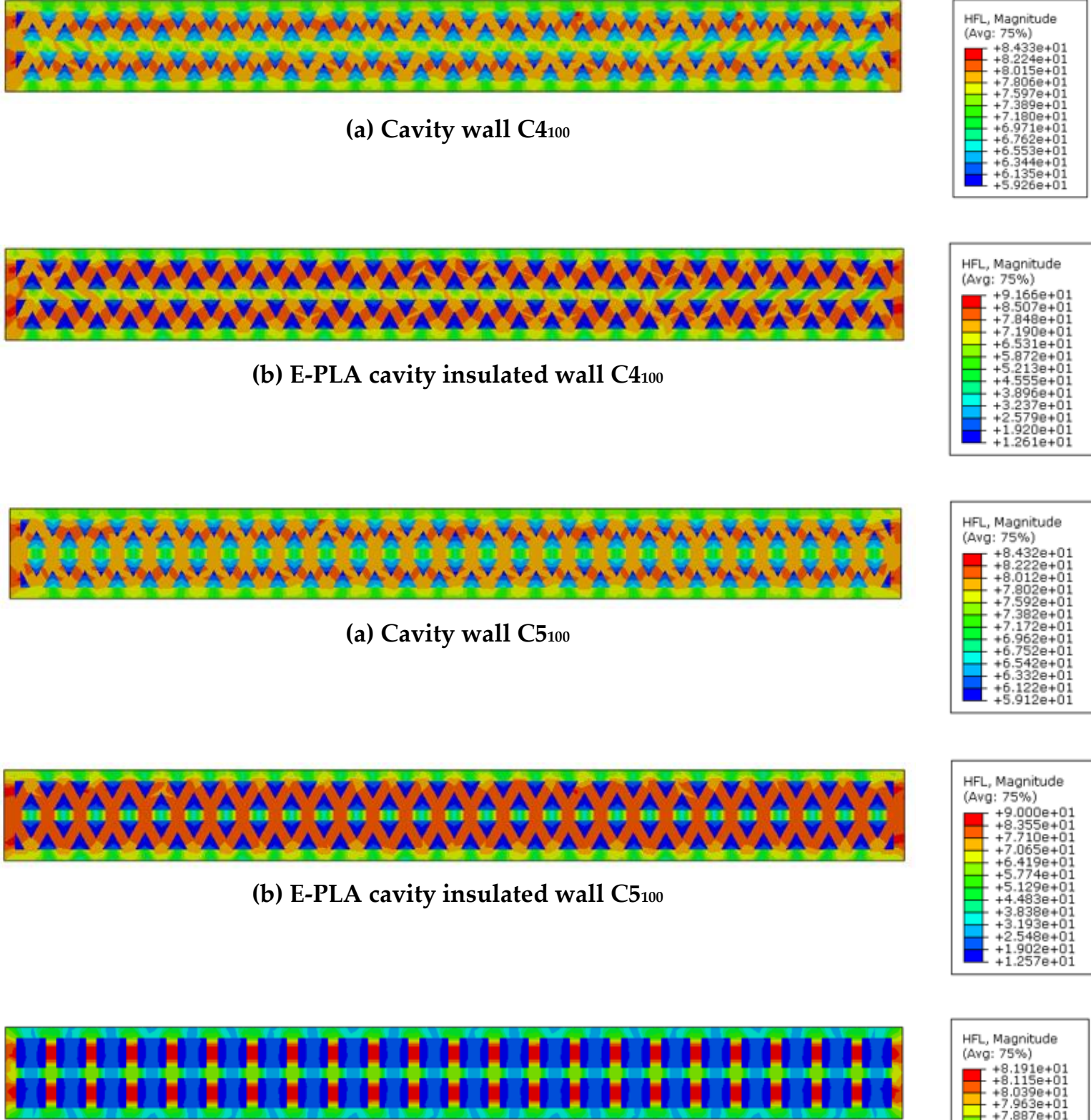

(a) Cavity wall C6100

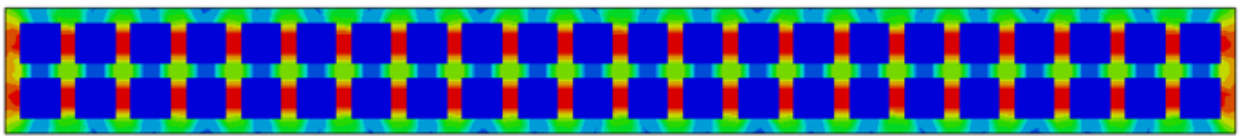

(b) E-PLA cavity insulated wall C6100
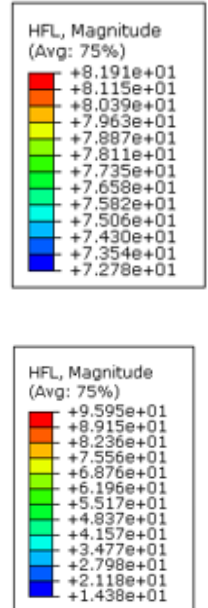

Figure 11. Cont. 


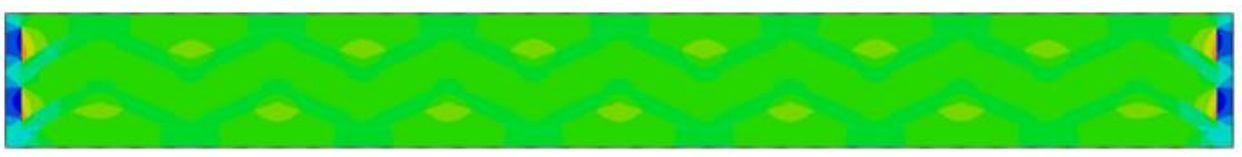

(a) Cavity wall C7100
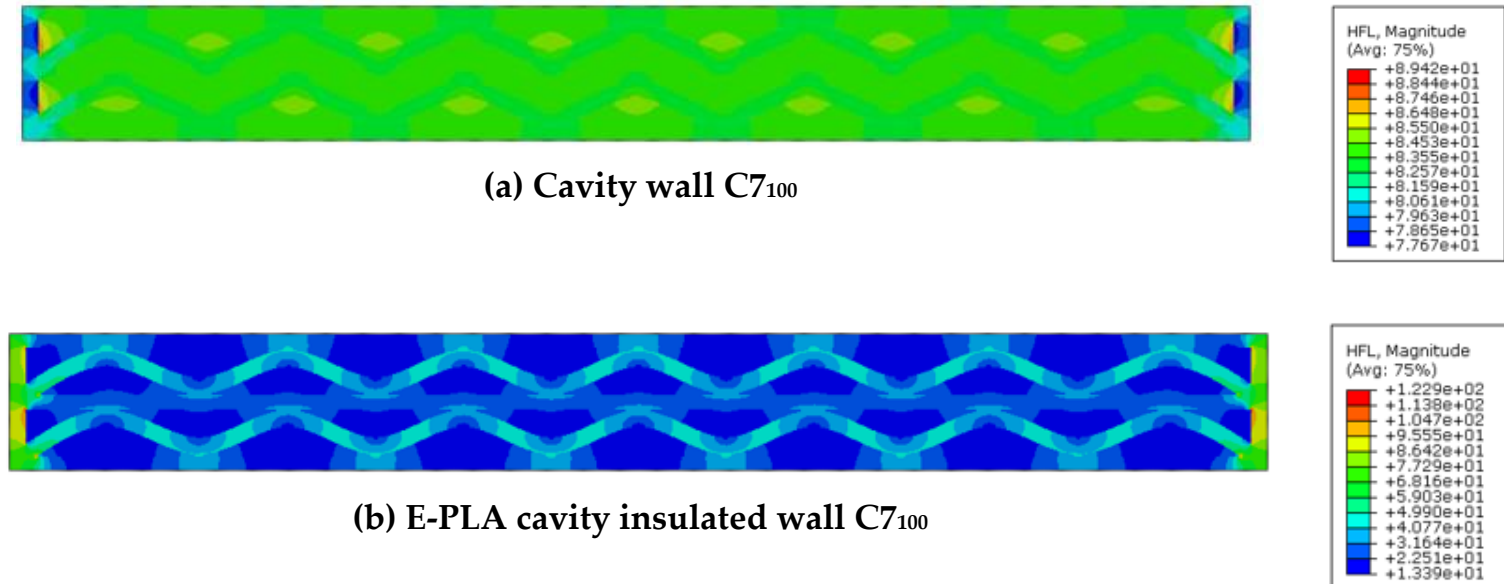

(b) E-PLA cavity insulated wall C7100

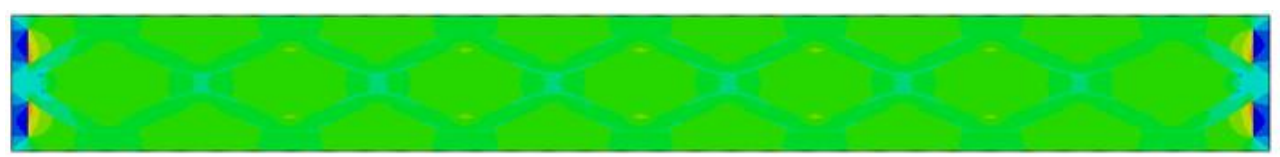

(a) Cavity wall C8100
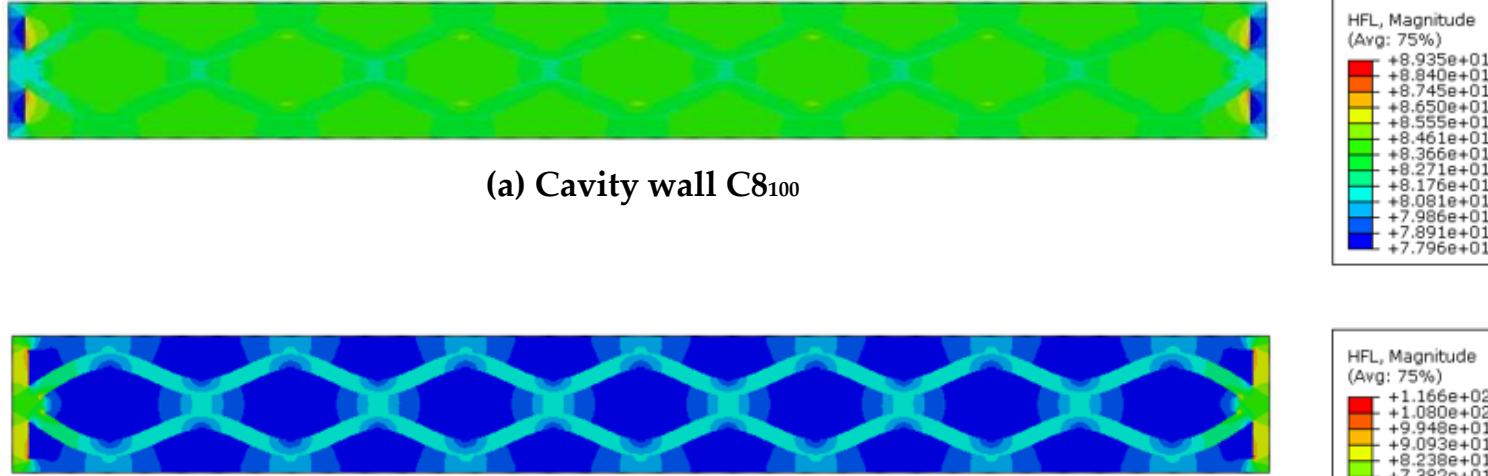

(b) E-PLA C cavity insulated wall 8100

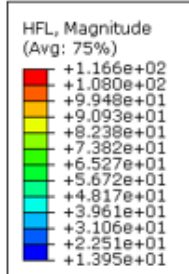

Figure 11. Heat-flux colour distribution along the $100 \mathrm{~mm}$ wall configurations. 


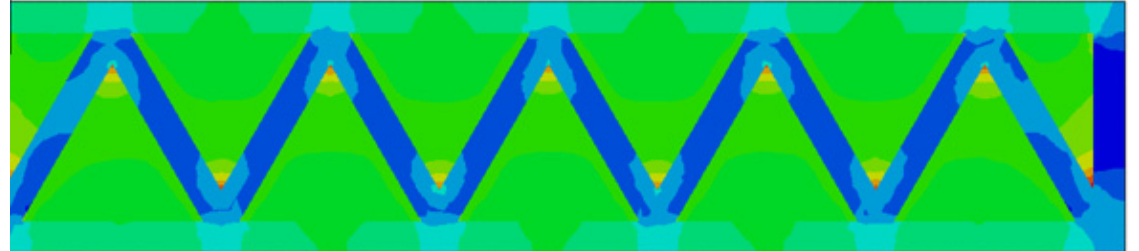

(a) Cavity wall $\mathrm{C1}_{200}$

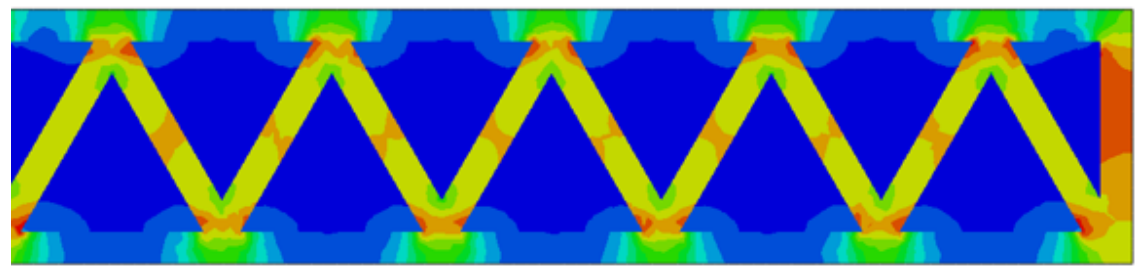

(b) E-PLA cavity insulated wall C1200

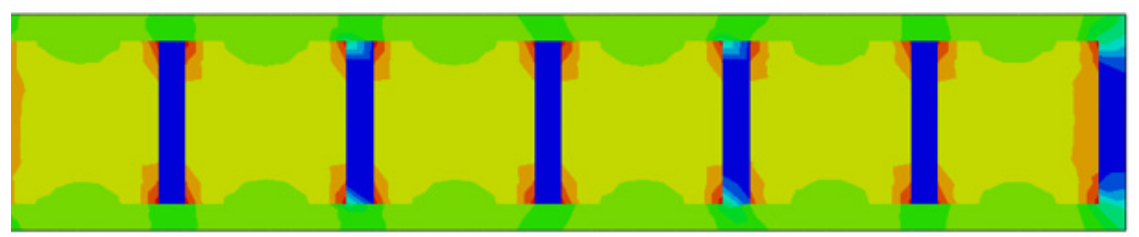

(a) Cavity wall C2200

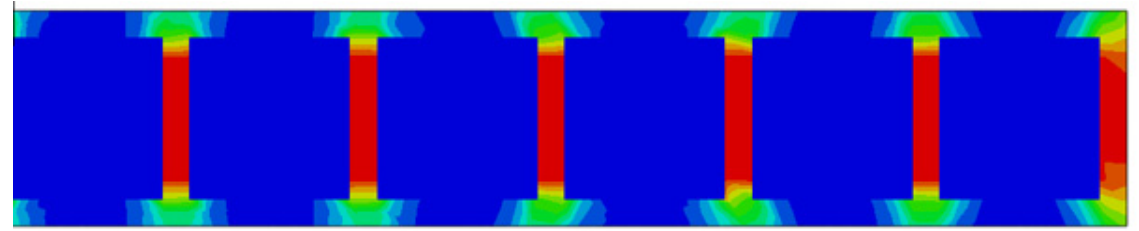

(b) E-PLA cavity insulated wall C2200

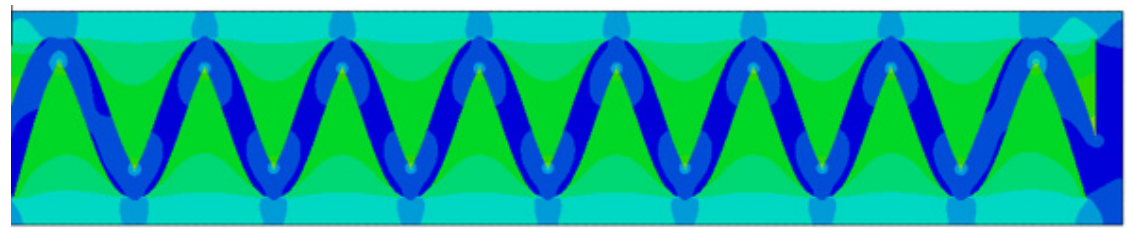

(a) Cavity wall C3200

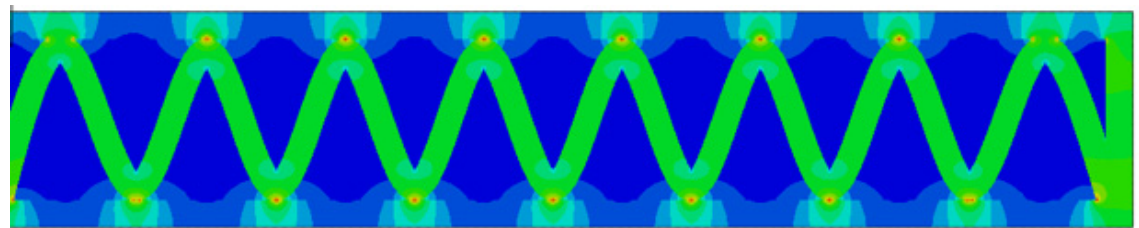

(b) E-PLA cavity insulated wall C3200
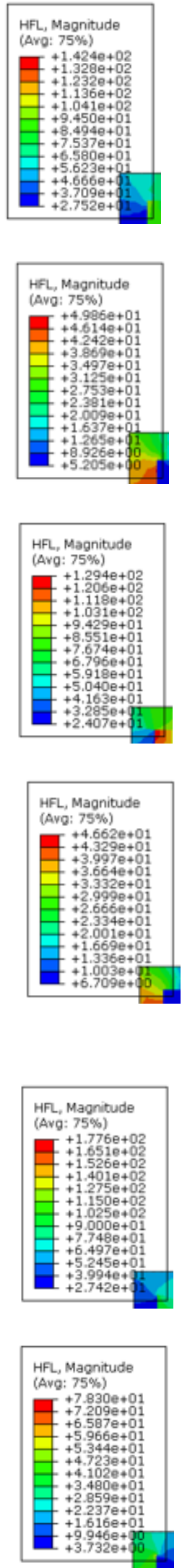

Figure 12. Cont. 


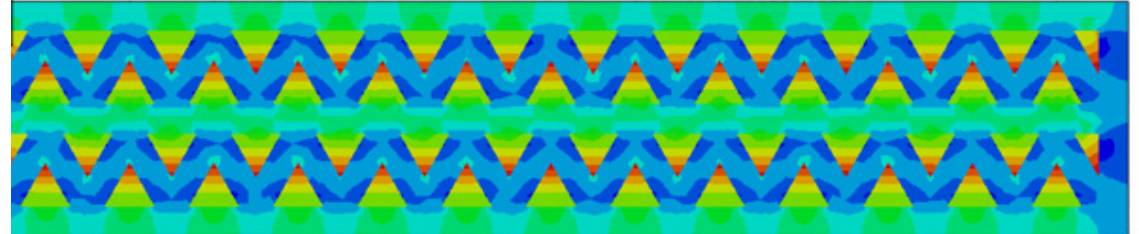

(a) Cavity wall C4200

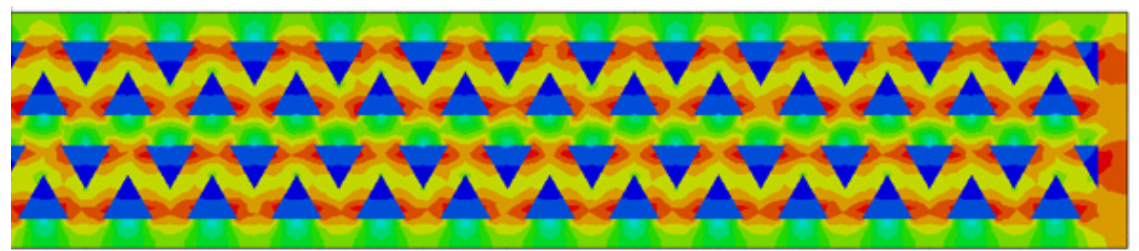

(b) E-PLA cavity insulated wall C4200

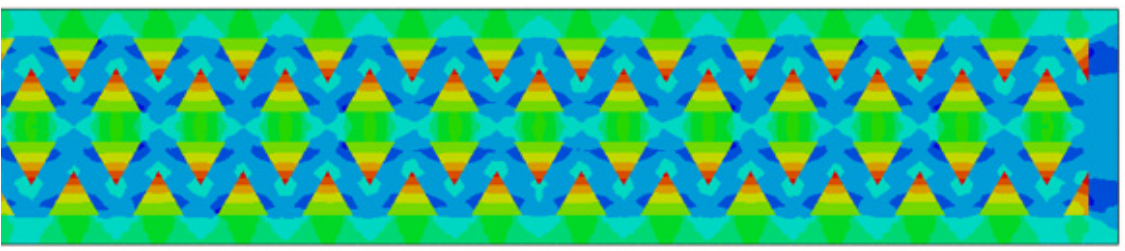

(a) Cavity wall C5200

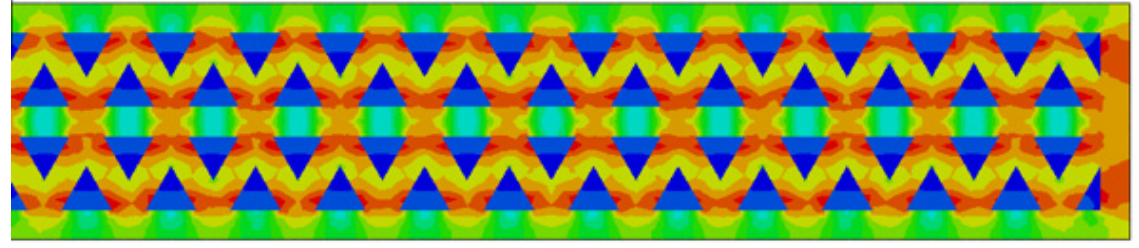

(b) E-PLA cavity insulated wall $\mathrm{C}_{200}$

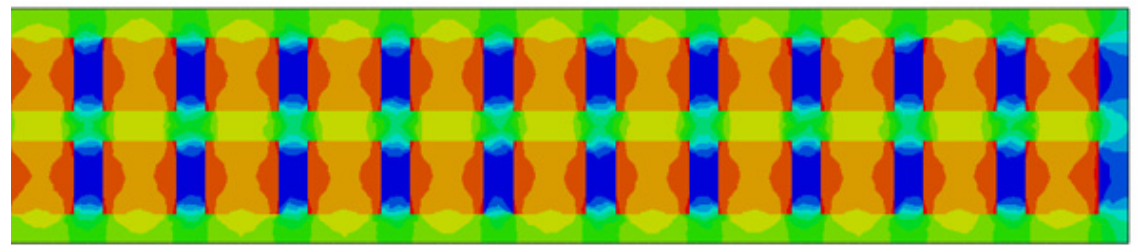

(a) Cavity wall C6200

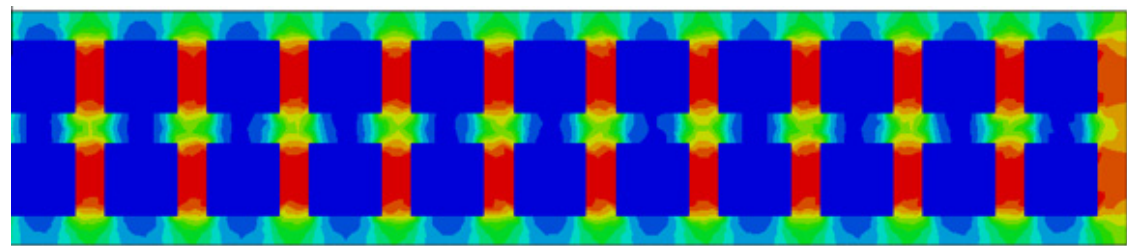

(b) E-PLA cavity insulated wall C6200
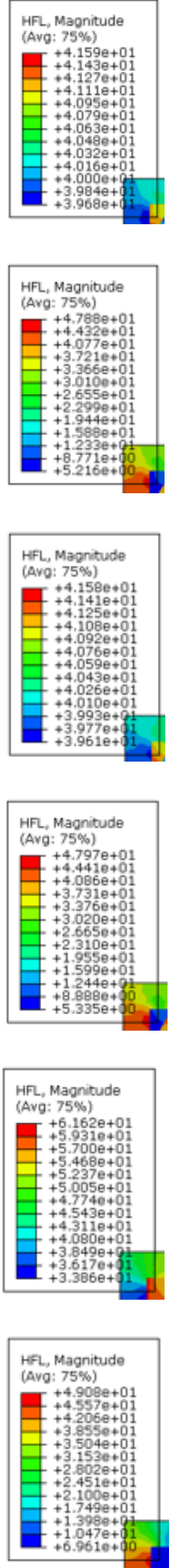

Figure 12. Cont. 


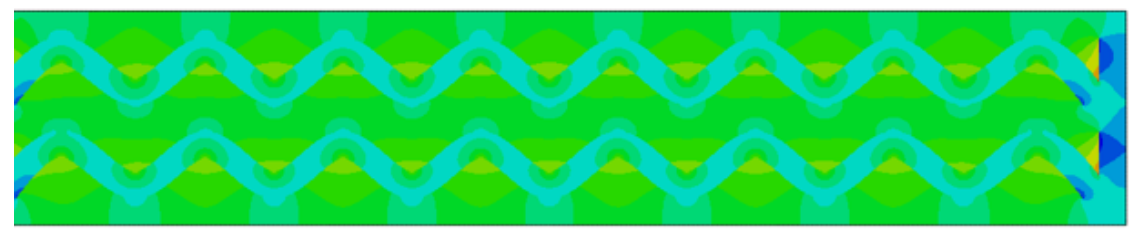

(a) Cavity wall C7 $7_{200}$

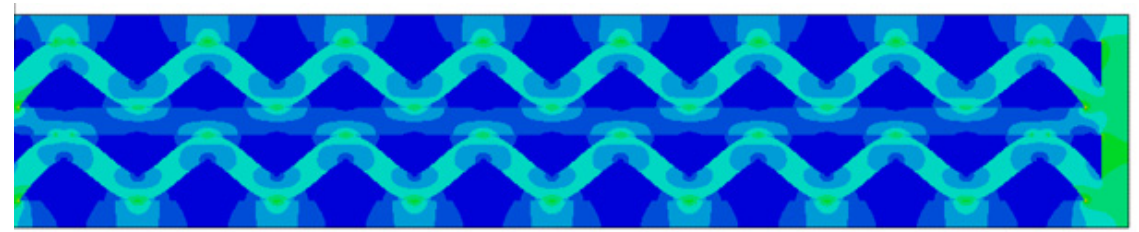

(b) E-PLA C cavity insulated wall 7200

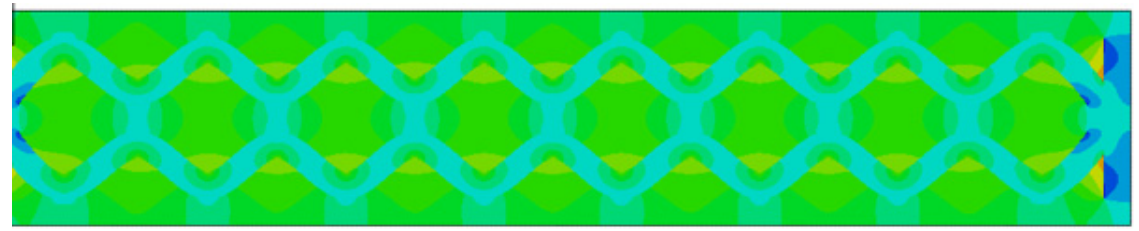

(a) Cavity wall C8200

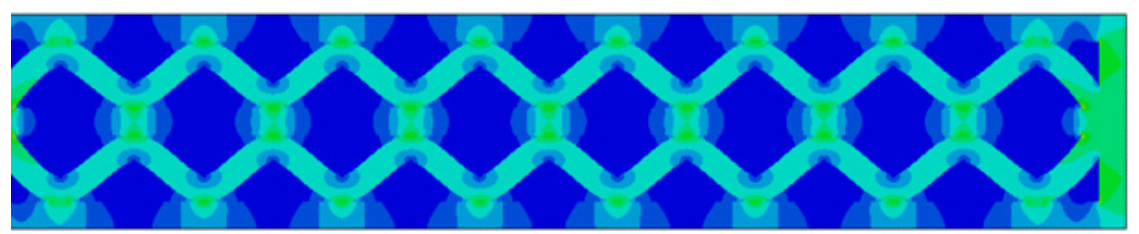

(b) E-PLA cavity insulated wall C8200
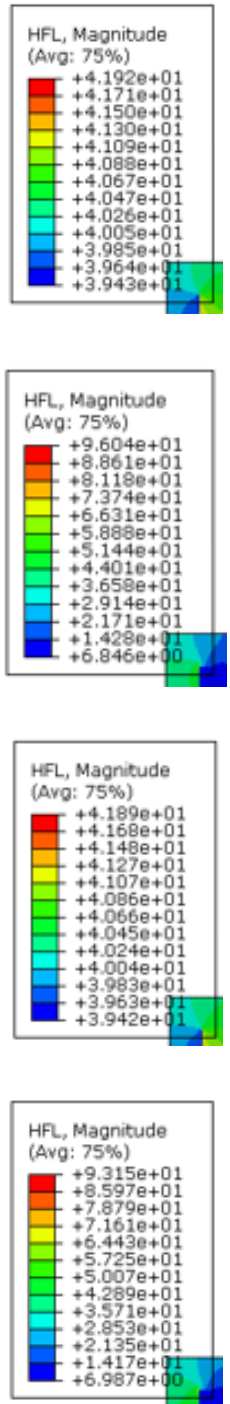

Figure 12. Heat-flux colour distribution along the $200 \mathrm{~mm}$ wall configurations.

Thermal bridging can be observed through concrete, as shown in the contour plots in Figures 11 and 12. Thermal conductivity was approximately 10 times higher in concrete than in air or E-PLA (Tables 1 and 2), which created a thermal bridge from the concrete. However, this study did not consider any particular relative humidity condition in determining the dew point. The study intended to emphasize the effect of different configurations on the thermal performance (U-value) with air voids and with insulation material filling. Any interested user can use the study results and, by using standard relationships, could calculate the dew point with available relative humidity.

\section{Proposal of Equation for the Estimation of U-Value of 3DPC Cavity Walls}

The theoretical equation to calculate the U-value of a wall panel is given in Equation (1). This equation can be directly used for rectangular columns having different layers of materials. However, it cannot be directly used for 3DPC walls, since the walls' geometry is complex. The development and analysis of FE modelling was used for determining the U-value of the complex-shaped 3DPC walls in this study. However, FE modelling takes time and requires expert knowledge in FE modelling techniques. Therefore, a simple equation was derived to determine the U-values of the 3DPC cavity walls with complex geometries. From the above analysis, it was identified that the thermal conductivity of cavity and concrete and the cross-sectional area of concrete panel and the cavity had a 
clear influence on the thermal energy performance of the 3DPC wall configurations. Hence, Equation (5) is proposed to calculate the U-values of $100 \mathrm{~mm}$ thickness cavity wall panels with different cross-sectional arrangements with the aforementioned parameters. The U-values calculated using the proposed equation were compared with FE results, and are illustrated below in Table 8. The mean and COV values of comparison were calculated, and were 1.0 and 0.02 , respectively. Therefore, the equation gave the best prediction of FE values for the U-values, and thus the thermal behaviour of $100 \mathrm{~mm}$ thickness cavity wall panels. However, further analysis must be performed to determine a similar kind of relationship for U-values with these parameters for wall panels with different thicknesses and cavity insulation.

Table 8. Comparison of U-values.

\begin{tabular}{|c|c|c|c|c|c|c|c|c|c|c|}
\hline Wall & $\begin{array}{c}\text { Cavity } \\
\text { Area }\left(\mathrm{m}^{2}\right)\end{array}$ & $\begin{array}{c}\text { Concrete } \\
\text { Area }\left(\mathrm{m}^{2}\right)\end{array}$ & $\begin{array}{l}\text { Avg Cavity } \\
\text { Thickness } \\
\text { (m) }\end{array}$ & $\begin{array}{c}\text { Avg } \\
\text { Concrete } \\
\text { Thickness } \\
\text { (m) }\end{array}$ & $\begin{array}{c}\lambda c \\
\left(\mathrm{~W} / \mathrm{m}^{2} \cdot \mathrm{K}\right)\end{array}$ & $\begin{array}{c}\lambda \mathrm{s} \\
\left(\mathrm{W} / \mathrm{m}^{2} \cdot \mathrm{K}\right)\end{array}$ & R Value & $\begin{array}{c}\text { U Value } \\
\text { Equation } \\
\text { (5) }\end{array}$ & $\begin{array}{c}\text { U Value } \\
\text { FEM }\end{array}$ & Equation/FEM \\
\hline $\mathrm{C} 1_{100}$ & 52519 & 47481 & 0.05 & 0.05 & 0.36 & 0.2 & 0.39 & 2.60 & 2.68 & 0.97 \\
\hline $\mathrm{C} 2100$ & 64144 & 35856 & 0.06 & 0.04 & 0.42 & 0.2 & 0.33 & 3.02 & 3.16 & 0.96 \\
\hline $\mathrm{C} 3100$ & 57174 & 42826 & 0.06 & 0.04 & 0.36 & 0.2 & 0.38 & 2.67 & 2.79 & 0.96 \\
\hline $\mathrm{C} 4_{100}$ & 23923 & 76077 & 0.02 & 0.08 & 0.14 & 0.2 & 0.55 & 1.83 & 1.85 & 0.99 \\
\hline $\mathrm{C} 5_{100}$ & 23923 & 76077 & 0.02 & 0.08 & 0.14 & 0.2 & 0.55 & 1.83 & 1.85 & 0.99 \\
\hline $\mathrm{C} 6_{100}$ & 45568 & 54432 & 0.05 & 0.05 & 0.18 & 0.2 & 0.53 & 1.89 & 1.89 & 1.00 \\
\hline C7 100 & 37736 & 62264 & 0.04 & 0.06 & 0.22 & 0.2 & 0.48 & 2.08 & 2.09 & 0.99 \\
\hline \multirow[t]{3}{*}{$\mathrm{C} 8_{100}$} & 37736 & 62264 & 0.04 & 0.06 & 0.22 & 0.2 & 0.48 & 2.08 & 2.09 & 0.99 \\
\hline & & & & & & & & & Mean & 1.00 \\
\hline & & & & & & & & & COV & 0.02 \\
\hline
\end{tabular}

Note: $\lambda \mathrm{c}$ : thermal conductivity of cavity; $\lambda \mathrm{s}$ : thermal conductivity of solid; $\mathrm{A}_{\mathrm{T}}$; total area of the wall section; Ac: cavity area of the wall section; Lw: length of the wall section.

$$
\mathrm{U}-\text { value }=\frac{\lambda_{\mathcal{c}} \lambda_{s}}{\lambda_{s}\left(\frac{A_{c}}{L_{w}}\right)+\frac{\lambda_{\mathcal{C}}\left(A_{T}-A_{C}\right)}{L_{w}}}
$$

\section{Conclusions}

The 3DPC technology used here is a developing construction method at present, and its applications are currently being subjected to many research studies. However, not enough research has been conducted to identify the appropriateness of these innovative construction technologies, and there is an ongoing controversy as to whether they are an appropriate replacement for traditional construction techniques. Moreover, there is a clear absence of investigations on the energy performance of 3DPC wall panels. Hence, this study investigated the energy performance of 3DPC wall configurations using numerical simulations. A series of 32 simulations with different 3DPC wall configurations were performed, aiming to determine the U-values. Based on the simulation results, the following conclusions were drawn:

- U-values of cavity walls generally decreased with increased wall thickness, regardless of the cross-sectional configurations;

- A significant reduction in the U-value was recognized for $100 \mathrm{~mm}$ wall panels with an additional intermediate row compared to single-row panels;

- Triangular-shaped cavity wall panels of $100 \mathrm{~mm}$ thickness displayed the highest performance, with lower U-values compared to other configurations. Double-row triangular and sinusoid-shaped $200 \mathrm{~mm}$ thickness cavity wall panels showed higher performance compared to other walls. However, the U-values were noticeably higher than the standard values. Thus, expanded polylactic acid (E-PLA) was used as thermal insulation material to enhance the performance;

- The incorporation of E-PLA material as the insulation reduced the U-value, and thus increased the thermal performance of the wall panels for all the configurations;

- The lowest obtained thermal transmittance value in this study was $0.34 \mathrm{~W} / \mathrm{m}^{2} \cdot \mathrm{K}$, for the $200 \mathrm{~mm}$ thickness wall configuration with a double-row lattice arrangement with E-PLA insulation $\left(\mathrm{C6}_{200}\right)$; 
- There was an evident relationship with void area and energy performance of 3DPC walls with the integration of insulation material;

- An equation was proposed to determine the U-values of $100 \mathrm{~mm}$ thickness cavity wall panels with complex cross-sectional configurations without using FE modelling.

This study is the first step towards enhancing the understanding of the thermal energy performance of 3DPC walls. However, the influence on fire and structural performance has not been analysed yet. Hence, further studies on different mixes and cavity-filling materials could be performed for further optimization.

Author Contributions: Conceptualization: K.P.; performed the numerical simulations and analysis: I.U. and T.S.; results interpretation: I.U., T.S., and K.P.; writing—original draft preparation: T.S., I.U. and P.G.; writing-review and editing: T.S., I.U., P.G., K.P., B.N. and P.S.; visualization: T.S. and H.R.; supervision: K.P. and B.N. All authors have read and agreed to the published version of the manuscript.

Funding: This research study is funded by Research Development Fund (RDF), Northumbria University.

Institutional Review Board Statement: Not applicable.

Informed Consent Statement: Not applicable.

Data Availability Statement: Not applicable.

Acknowledgments: The authors would like to acknowledge the financial and technical support of Northumbria University and University of Sri Jayewardenepura.

Conflicts of Interest: The authors declare no conflict of interest.

\section{References}

1. Di Foggia, G. Energy efficiency measures in buildings for achieving sustainable development goals. Heliyon 2018, 4, e00953. [CrossRef] [PubMed]

2. Santos, P.; Gonçalves, M.; Martins, C.; Soares, N.; Costa, J.J. Thermal transmittance of lightweight steel framed walls: Experimental versus numerical and analytical approaches. J. Build. Eng. 2019, 25, 100776. [CrossRef]

3. Lima, L.; Trindade, E.; Alencar, L.; Alencar, M.; Silva, L. Sustainability in the construction industry: A systematic review of the literature. J. Clean. Prod. 2020, 289, 125730. [CrossRef]

4. Murtagh, N.; Scott, L.; Fan, J. Sustainable and resilient construction: Current status and future challenges. J. Clean. Prod. 2020, 268, 122264. [CrossRef]

5. Yüksek, I.; Karadayi, T.T. Energy-Efficient Building Design in the Context of Building Life Cycle. Energy Effic. Build. 2017, 1-20. [CrossRef]

6. Lohmann, V.; Santos, P. Trombe Wall Thermal Behavior and Energy Efficiency of a Light Steel Frame Compartment: Experimental and Numerical Assessments. Energies 2020, 13, 2744. [CrossRef]

7. Al-Ghamdi, K.A. Sustainable FDM additive manufacturing of ABS components with emphasis on energy minimized and time efficient lightweight construction. Int. J. Light. Mater. Manuf. 2019, 2, 338-345. [CrossRef]

8. Jacobs, J. Concrete for Energy-Efficient Buildings, The Benefits of Thermal Mass; European Concrete Platform: Brussels, Belgium; British Cement Association: Camberley, UK ; British Ready-Mixed Concrete Association: London, UK; British Precast Concrete Federation: Glenfield, UK; The Cement Admixtures Association: Solihull, UK, 2007.

9. Paul, S.C.; Van Zijl, G.P.; Tan, M.J.; Gibson, I. A review of 3D concrete printing systems and materials properties: Current status and future research prospects. Rapid Prototyp. J. 2018, 24, 784-798. [CrossRef]

10. Al Rashid, A.; Khan, S.A.; Al-Ghamdi, S.G.; Koç, M. Additive manufacturing: Technology, applications, markets, and opportunities for the built environment. Autom. Constr. 2020, 118, 103268. [CrossRef]

11. Luhar, S.; Suntharalingam, T.; Navaratnam, S.; Luhar, I.; Thamboo, J.; Poologanathan, K.; Gatheeshgar, P. Sustainable and Renewable Bio-Based Natural Fibres and Its Application for 3D Printed Concrete: A Review. Sustainability 2020, 12, 10485. [CrossRef]

12. Khan, S.A.; Koç, M.; Al-Ghamdi, S.G. Sustainability assessment, potentials and challenges of 3D printed concrete structures: A systematic review for built environmental applications. J. Clean. Prod. 2021, 303, 127027. [CrossRef]

13. Chen, Y.; Çopuroğlu, O.; Rodriguez, C.R.; Filho, F.F.D.M.; Schlangen, E. Characterization of air-void systems in 3D printed cementitious materials using optical image scanning and X-ray computed tomography. Mater. Charact. 2021, 173, 110948. [CrossRef]

14. Ooms, T.; Vantyghem, G.; Van Coile, R.; De Corte, W. A parametric modelling strategy for the numerical simulation of 3D concrete printing with complex geometries. Addit. Manuf. 2021, 38, 101743. [CrossRef] 
15. Nguyen-Van, V.; Panda, B.; Zhang, G.; Nguyen-Xuan, H.; Tran, P. Digital design computing and modelling for 3-D concrete printing. Autom. Constr. 2021, 123, 103529. [CrossRef]

16. Cuevas, K.; Chougan, M.; Martin, F.; Ghaffar, S.H.; Stephan, D.; Sikora, P. 3D printable lightweight cementitious composites with incorporated waste glass aggregates and expanded microspheres-Rheological, thermal and mechanical properties. J. Build. Eng. 2021, 44, 102718. [CrossRef]

17. Song, J.; Cao, M.; Cai, L.; Zhou, Y.; Chen, J.; Liu, S.; Zhou, B.; Lu, Y.; Zhang, J.; Long, W.; et al. 3D printed polymeric formwork for lattice cementitious composites. J. Build. Eng. 2021, 43, 103074. [CrossRef]

18. Baduge, S.K.; Navaratnam, S.; Abu-Zidan, Y.; McCormack, T.; Nguyen, K.; Mendis, P.; Zhang, G.; Aye, L. Improving performance of additive manufactured (3D printed) concrete: A review on material mix design, processing, interlayer bonding, and reinforcing methods. Structures 2021, 29, 1597-1609. [CrossRef]

19. Hou, S.; Duan, Z.; Xiao, J.; Ye, J. A review of 3D printed concrete: Performance requirements, testing measurements and mix design. Constr. Build. Mater. 2021, 273, 121745. [CrossRef]

20. Xiao, J.; Liu, H.; Ding, T. Finite element analysis on the anisotropic behavior of 3D printed concrete under compression and flexure. Addit. Manuf. 2021, 39, 101712. [CrossRef]

21. Suiker, A. Mechanical performance of wall structures in 3D printing processes: Theory, design tools and experiments. Int. J. Mech. Sci. 2018, 137, 145-170. [CrossRef]

22. Panda, B.; Lim, J.H.; Tan, M.J. Mechanical properties and deformation behaviour of early age concrete in the context of digital construction. Compos. Part B Eng. 2019, 165, 563-571. [CrossRef]

23. Santos, P.; Lemes, G.; Mateus, D. Thermal Transmittance of Internal Partition and External Facade LSF Walls: A Parametric Study. Energies 2019, 12, 2671. [CrossRef]

24. Wang, L.; Jiang, H.; Li, Z.; Ma, G. Mechanical behaviors of 3D printed lightweight concrete structure with hollow section. Arch. Civ. Mech. Eng. 2020, 20, 1-17. [CrossRef]

25. 3D Printed Building in SIP. [image]. Available online: http://www.sipac.gov.cn/english/categoryreport/IndustriesAndEnterpr ises/201611/t20161129_506766.htm (accessed on 13 April 2021).

26. INNOVATIVE METHODS FOR REINFORCED CONCRETE. [image]. Available online: https://www.etesias.it/en/about-en.h tml (accessed on 15 April 2021).

27. Gosselin, C.; Duballet, R.; Roux, P.; Gaudillière, N.; Dirrenberger, J.; Morel, P. Large-scale 3D printing of ultra-high performance concrete-A new processing route for architects and builders. Mater. Des. 2016, 100, 102-109. [CrossRef]

28. Piroozfar, A.E.; Larsen, O.P.; Altan, H.; Piller, F.T.; Tseng, M.M. Customization in Building Design and Construction: A Contribution to Sustainability. In Handbook of Research in Mass Customization and Personalization; World Scientific Pub Co Pte Lt.: London, UK, 2009; pp. 911-939.

29. Pessoa, S.; Guimarães, A.; Lucas, S.; Simões, N. 3D printing in the construction industry - A systematic review of the thermal performance in buildings. Renew. Sustain. Energy Rev. 2021, 141, 110794. [CrossRef]

30. Marais, H.; Christen, H.; Cho, S.; De Villiers, W.; Van Zijl, G. Computational assessment of thermal performance of 3D printed concrete wall structures with cavities. J. Build. Eng. 2021, 41, 102431. [CrossRef]

31. Alkhalidi, A.; Hatuqay, D. Energy efficient 3D printed buildings: Material and techniques selection worldwide study. J. Build. Eng. 2020, 30, 101286. [CrossRef]

32. He, Y.; Zhang, Y.; Zhang, C.; Zhou, H. Energy-saving potential of 3D printed concrete building with integrated living wall. Energy Build. 2020, 222, 110110. [CrossRef]

33. Craveiro, F.; Bartolo, H.; Gale, A.; Duarte, J.; Bartolo, P. A design tool for resource-efficient fabrication of 3d-graded structural building components using additive manufacturing. Autom. Constr. 2017, 82, 75-83. [CrossRef]

34. ABAQUS. Hibbitt; Karlsson \& Sorensen, Inc.: Pawtucket, RI, USA, 2021. 